\title{
MFG-E8 Signaling Promotes Elastolysis and Calcification in the Aging Aortic Wall
}

Soo Hyuk Kim, Lijuan Liu, Leng Ni, Li Zhang, Jing Zhang, Yushi Wang, Kimberly R. McGraw, Robert Monticone, Richard Telljohann, Edward G. Lakatta, Mingyi Wang. Laboratory of Cardiovascular Science, National Institution on Aging, National Institutes of Health, Biomedical Research Center (BRC), 251 Bayview Boulevard, Baltimore, MD 21224, USA.

Running title: MFG-E8 Signaling, Elastolysis, and Calcification

Correspondence to Mingyi Wang, MD, PhD, FAHA

Laboratory of Cardiovascular Science

National Institution on Aging

National Institutes of Health

Biomedical Research Center (BRC)

251 Bayview Boulevard, Baltimore, MD 21224, USA

Email: mingyiw@grc.nia.nih.gov

Tel: (+1)410-558-8112

Keyword: Vascular smooth muscle cells $\bullet$ Milk fat globule epidermal growth factor VIII $\bullet$ Matrix metalloprotein type II $\bullet$ p38 signaling $\bullet$ Tropoelastin $\bullet$ Elastolysis $\bullet$ Calcification $\bullet$

Subject codes: Vascular biology• Inflammation• extracellular remodeling 


\begin{abstract}
Objective- The proinflammatory phenotypic shift of vascular smooth muscle cells (VSMCs) is closely linked to the elastolysis and calcification in the aging arterial wall. Degradation of tropoelastin (TPELN) is a key molecular event which often accompanies the proinflammatory phenotypic shift of VSMCs, arterial elastolysis and calcification with aging. Milk fat globuleEGF factor 8 (MFG-E8), secreted mainly from VSMCs, predominantly binds to degenerated elastin fibers, and alters VSMCs phenotypes. Here, we investigated how MFG-E8 proinflammatory signaling in the arterial wall, in vivo, and VSMCs, in vitro, affects arterial elastolysis and calcification with advancing age.
\end{abstract}

Methods and Results-In vivo immunostaining and immunoblotting studies indicated that MFGE8, elastic lamina breaks, and calcium-phosphorus products were markedly increased while intact TPELN ( 70Kda) protein was dramatically decreased in aortic walls or isolated aortic VSMCs harvested from old (30-month-old) vs. young (8-month-old) Fischer $344 \times$ Brown Norway rats (FXBN). In vitro studies demonstrated that (1) treating either young or old VSMCs to recombinant human MFG-E8 (rhMFG-E8) for 24 hours significantly reduced intact TPLEN levels and this effect was reduced by SB203580, a p38 mitogen-activated protein kinase inhibitor; (2) activated MMP-2 levels were significantly increased in both young and old VSMCs treated with rhMFGE8, and this activation was also inhibited by SB203580; (3) MMP-2 physically interacted with TPLEN and cleaved intact TPLEN from VSMCs; (4) downregulation of either MFG-E8 or MMP2 in VSMCs via siRNA significantly increased the levels of intact TPELN; (5) rhMFG-E8 treatment markedly reduced contractile protein, smooth muscle 22-alpha, and anti-calcification protein, fetuin-A, levels in both young and old VSMCs, which were blocked by SB203580. Notably, MMP-2 activity, elastic laminae degeneration, and calcium deposits were significantly increased while fetuin-A levels are markedly decreased in old WT vs. MFG-E8 mice.

Conclusions- Taken together, our current findings suggest that MFG-E8, via p38 signaling in VSMCs, promotes MMP-2-associated elastolysis and calcification in the aging arterial wall. 


\begin{tabular}{|l|l|}
\hline \multicolumn{2}{|l|}{ Nonstandard Abbreviations and Acronyms } \\
\hline MFG-E8 & milk fat globule epidermal growth factor VIII \\
\hline p38 & p38 mitogen-activated protein kinase \\
\hline MMP-2 & matrix metalloproteinase type 2 \\
\hline rhMFG-E8 & recombinant human MFG-E8 \\
\hline TPELN & tropoelastin \\
\hline VSMCs & vascular smooth muscle cells \\
\hline
\end{tabular}




\section{Introduction}

Aging is the major risk factor for quintessential cardiovascular diseases, such as hypertension, due mainly to adverse arterial proinflammatory remodeling ${ }^{1-3}$. With advancing age, the arterial wall becomes less resilient and stiffens, resulting mainly from a cascade of the breakdown and calcification of the elastic network, and from the proinflammation of vascular smooth muscle cells $(\mathrm{VSMCs})^{1-8}$.

The elastic network within the aged arterial wall collapses due mainly to the cleavage by activated matrix metalloproteinase type 2 (MMP2), known as elastolysis ${ }^{8-11}$. Tropoelastin (TPELN), a monomeric precursor to elastin, is a core protein in the assembly of the elastic network and plays an important role in maintaining VSMCs quiescent phenotype and elastic network integrity and cardiovascular health ${ }^{5,6,12,13}$. Elastolysis is often accompanied by a decrease in the levels of intact TPELN protein with aging ${ }^{6,9,14}$. The in vivo and in vitro studies have shown that the fractured ends or eroded points of arterial elastin fragments have a high affinity for calciumphosphorus products, which become a nucleation site for deposition of hydroxyapatite crystals, an impetus for initiating and propagating arterial calcification ${ }^{8} 15,16$.

The smooth muscle specific protein 22 alpha (SM22 $\alpha$ ) is an early molecular marker of differentiation, and a molecule that suppresses inflammation in VSMCs ${ }^{17-19}$. SM22 $\alpha$ is enriched in differentiated VSMCs and increased levels are found in young arterial walls while old show decreased amounts $10,17,20$. Thus, aged VSMCs appear dedifferentiated and proinflammed ${ }^{1,2} \cdot$ p3 $^{2}$ mitogen-activated protein kinase (p38), a stress-activated dedifferentiated signaling molecule, is increased in aging VSMCs ${ }^{21-25}$. The phosphorylation of p38 participates in the activation of MMP-2 of stressed VSMCs ${ }^{22}$. Both p38 and MMP-2 activation play causal roles in proinflammation of VSMCs, contributing to elastolysis and calcification in the arterial wall ${ }^{22-27}$.

Milk fat globule epidermal growth factor VIII (MFG-E8), a secreted extracellular glycoprotein, also known as lactadherin, plays multiple proinflammatory roles in the aging arterial wall $^{28-31}$. MFG-E8 signaling phenotypically shifts VSMCs into a dedifferentiated state with increases in invasion, proliferation, and proinflammation within the arterial wall with advancing age $^{29-31}$. In addition, MFG-E8 is a potent calcium binding protein, which has a strong affinity for elastic fibers and plays a bridging role in the bio-mineralization processes of VSMCs and matrix in arterial walls ${ }^{32-34}$.

In the present study, we investigated a novel MFG-E8 signaling pathway in VSMCs that induces activation of MMP-2 via p38 activation, contributing to an increase in the elastolysis and calcification in the aging arterial wall. Thus, intervening MFG-E8 signaling is a potentially novel approach to maintaining arterial health with aging. 


\section{Materials \& Methods}

The authors declare that all supporting data are available within the article.

\section{Experimental animals}

\section{Rats}

All procedures were performed per protocols approved by the National Institute on Aging (NIA) in accordance with the National Institute of Health (NIH) Animal Care and Use Committee. Eightmonth-old (8mo, young) and 30-month-old (30mo, old) male Fisher 344 crossbred Brown Norway (FXBN) rats were obtained from NIA Aged Rodent Colonies. Animals were sacrificed and thoracic aortae were harvested as previously described ${ }^{35}$. Aortic tissues were embedded in paraffin for histological study and fresh tissue were snap-frozen in liquid nitrogen $\left(\mathrm{LN}_{2}\right)$ for western blotting and real time polymerase chain reaction (RT-PCR) analysis. In addition, aortic tissues harvested from young and old FXBN rats ( $n=4 /$ age group) were flatly embedded in paraffin. Longitudinal or cross-sectional ( $5 \mu \mathrm{m}$ in thickness) aortic walls were employed for histology and histochemistry staining, including hematoxylin \& eosin (HE), Masson's trichrome, elastic tissue fibers Verhoeff's Van Gieson (EVG), Alizarin Red S, and von Kossa staining, according to the instruction of manufacture (Polysciences, Inc. Warrington PA), and morphometric analyses (MetaMorph Microscopy Automation and Image Analysis Software, Molecular Devices, LLC, CA ) as described previously, 95,36 .

\section{Mice}

All experiments were performed according to the protocols approved by the NIA in accordance with the NIH Animal Care and Use Committee. MFG-E8 knock out (KO) mice were obtained from Dr. Mark Udey at National Cancer Institute (NCI), and generated, characterized, and genotyped as described previously. ${ }^{37,38}$ Mice were genotyped by PCR using the following primers: Rip1-Tag2, GGACAAACCACAACTAGAATGCAGTG (forward) and CAGAGCAGAATTGTGGAGTGG (reverse); Neo, GCCAGAGGCCACTTGTGTAG; and MFG-E8, CTCTCAGATTCACCTGCTCGTG and CACCGTTCAGGCACAGGCTG. Animals were housed and used in experiments in accordance with institutional guidelines. Complete census of the MFG-E8 mouse colony was completed monthly, where body weights were collected. Aortic tissues harvested from old MFG-E8 KO (n=4; 40-week-old) and old WT (n=4, 97-week-old) were embedded in paraffin and sectioned for histology and histochemistry staining, including HE for general overview, Masson's trichrome for extracellular matrix, EVG for elastin fibers, Alizarin Red S for calcium deposits, according to the instruction of manufacture (Polysciences, Inc. Warrington PA), and morphometric analyses described previously ${ }^{9,35,36}$.

\section{Primary VSMCs isolation and culture}

All in vitro experiments were performed utilizing rat VSMCs which were enzymatically isolated from aortae of rats aged 8mo (young) and 30mo (old), as previously described ${ }^{10,29}$. Briefly, F344XBN rat thoracic aortae were rinsed in Hanks balanced salt solution (HBSS) containing 
$50 \mu \mathrm{g} / \mathrm{mL}$ penicillin, $50 \mu \mathrm{g} / \mathrm{mL}$ streptomycin and $0.25 \mu \mathrm{g} / \mathrm{mL}$ amphotericin B (Thermo Fisher Scientific, Lanham, MD, USA). After digestion for $30 \mathrm{~min}$ in $2 \mathrm{mg} / \mathrm{mL}$ of collagenase I solution (Worthington Biomedical, Freehold, NJ, USA) at $37^{\circ} \mathrm{C}$, the adventitia and intima were removed from the vessel medial layer and then were further digested with $2 \mathrm{mg} / \mathrm{mL}$ collagenase II $/ 0.5 \mathrm{mg} / \mathrm{mL}$ elastase (Sigma, Burlington, MA, USA) for 90-120 min at $37^{\circ} \mathrm{C}$. Isolated VSMCs were washed and plated in complete medium containing $20 \%$ fetal bovine serum (FBS) and cultured at $37^{\circ} \mathrm{C}$. Early passage (p3-p5) VSMCs were cultured in complete medium containing $10 \%$ FBS in the presence or absence of recombinant human MFG-E8 (rh-MFG-E8, R\&D Systems, Inc., Minneapolis, MN, USA), and SB203580, a p38 inhibitor (Santa Cruz Biotechnology, Dalla, TX, USA).

\section{Western blotting}

For western blotting, $10 \mu \mathrm{g}$ of whole cell lysates or arterial tissue lysates were resolved by SDSPAGE and transferred to a nitrocellulose membrane (Bio-rad, Hercules, California, USA). The transferred membranes were incubated in phosphate-buffered saline (PBS) containing primary antibodies at $4^{\circ} \mathrm{C}$ for 24 hours. Horseradish peroxidase (HRP)-conjugated IgG (Abcam, Cambridge, MA, USA) was used as a secondary antibody and detected with SuperSignal West Pico Chemiluminescent Substrate (Pierce Biotechnology, Rockford, IL, USA). Densitometric analysis of the bands by ImageJ from NIH image was obtained on the protein extracts from VSMCs of at least three independent experiments. See Table 1 for a list of primary antibodies.

\section{Quantitative real-time PCR}

Messenger ribonucleic acid (mRNA) was extracted from the thoracic aortae or early passage VSMCs of individual young and old rats using the RNA precipitation kit (Qiagen, Germantown, MD, USA). RNA (200ng) was isolated according to the manufacturer's instructions (Applied Biosystems, Foster City, CA, USA). All the primers used for Real Time PCR (RT-PCR) analysis was designed using Primer Express software 2.0 (Applied Biosystems, Foster City, CA, USA), and synthesized by Thermo Fisher Scientific (Carlsbad, CA, USA). The following primer sequences were used: TPELN, forward ATCGGAGGTCCAGGCATTG; and backward ACCAGCACCAACCCCGTAT. MFG-E8, forward ACACACAGCGAGGGGACAT; and backward ATCTGTGAATCGGCAATGG. H1f0, forward AGCCACTACAAGGTGGGTGAGA; and backward TTGAGAACACCGGTGGTCACT. Real-time PCR was performed according to the SYBR Green PCR protocol (Applied Biosystems, Foster City, CA, USA). Each sample was tested in quadruplicate with the following reaction conditions: $10 \mathrm{~min}$ at $95^{\circ} \mathrm{C}$ (one cycle); 30 second (sec) at $95^{\circ} \mathrm{C} ; 30 \mathrm{sec}$ at $60^{\circ} \mathrm{C}$; and $30 \mathrm{sec}$ at $72^{\circ} \mathrm{C}$ ( 40 cycles). Gene-specific PCR products were continuously measured by an ABI PRISM 7900 HT Sequence Detection System (PE Applied Biosystem Norwalk, CT, USA). The PCR product sizes were verified by agarose gel electrophoresis. Samples were normalized to the expression of the "housekeeping" gene, H1F0.

\section{Transfection of small interfering RNA (siRNA)}

MFG-E8 and MMP-2 siRNA was synthesized by Ambion of Thermo Fisher Scientific (Lanham, MD, USA). The following primer sequences were used: MFG-E8 forward GAACAUCUUUGAGAAACCUTT; and backward AGGUUUCUCAAAGAUGUUCTT. MMP- 
2 forward CCACUACGCUUUUCUCGAATT; and backward UUCGAGAAAAGCGUAGUGGAG. VSMCs were transfected for 48hr with scramble siRNA $(20 \mathrm{nM})$ or targeted protein siRNA $(20 \mathrm{nM})$ using liposome based RNAiMAX (Thermo Fisher Scientific, Lanham, MD, USA) according to the manufacturer's instructions.

\section{Gelatin Zymography}

For detection of MMP-2 activity, secreted by VSMCs, equal amounts of homogenous protein from VSMC $(10 \mu \mathrm{g})$ or aortic walls $(10 \mu \mathrm{g})$ and $2 \mathrm{x}$ sample buffer were mixed and loaded onto zymography gels (Invitrogen Novex Zymogram gels, Thermo Fisher Scientific, Lanham, MD, USA). The gel was renatured by incubation with NOVEX renaturing buffer for 30 minutes at room temperature and incubated in developing buffer at $37^{\circ} \mathrm{C}$ overnight. Finally, the gel was stained with $0.5 \%$ Coomassie blue, and then de-staining to visualize the proteolytic lysis bands, which were analyzed using ImageJ software.

\section{Construction and production of lentiviral plasmids}

Human elastin constructs were designed by using the pCMV-tag2B vector (Addgene, Watertown, MA) and were inserted between EcoRI and XhoI sites. The sequences used are as follows: FlagTPELN, forward CCCGGGCTGCAGGAATTCGCGGGTCTGACG, backward CCCCCCCTCGCGGTCGACTCATTTTCTCTT. VSMCs were transfected for $24 \mathrm{hr}$ with control vector (1ug) or targeted protein vector (1ug) using liposome based lipofectamine 2000 (Thermo Fisher Scientific, Lanham, MD, USA) according to the manufacturer's instructions.

\section{Statistical analysis}

All experiments were performed in triplicate from at least three independent experiments and three to six different rats. Data analysis was performed using GraphPad prism, and expressed as Mean \pm SEM. For two groups, comparison of means was made using Student's two-tailed test (T-test), and for more than two groups means were compared using one-way ANOVA with Tukey's multiple comparison test. A $\mathrm{p}<0.05$ was considered significant. 


\section{Results}

\section{Elastolysis and calcification in aging aortic walls}

Aging aversely remodels arterial walls. Morphometrical analysis of histochemical EVG staining of cross-sectional and en face aortic walls indicated that the breaks in the elastic meshwork of aortic elastin laminae, an index of elastolysis, was increased by 46-fold in old vs young rats (Fig. $1 A$ \& 1B) while the intercellular elastic fibers proportion of the elastic fraction, another index of elastolysis, was substantially decreased by $\sim 30 \%$ ( Fig. 1C \& 1D). In addition, there was a 1.5fold increase of collagen deposition in the aortic wall in old vs young rats (Fig. 1E \& 1F) as determined by Masson's trichrome staining. Importantly, Alizarin red staining demonstrated that calcium deposits (red color seen in Fig. 1G) were elevated by $33 \%$ in old vs young aortic walls (Fig. 1 H); and Von Kossa staining demonstrated that phosphorus deposits (black color seen in Fig. 1I) were elevated by 35 -fold in old vs young aortic walls (Fig. 1J).

\section{MFG-E8 and TPELN expression in aging aortic walls and VSMCs}

Both MFG-E8 and TPELN are altered in adverse arterial remodeling with aging. Immunofluorescence staining confirmed the previous findings that in old vs young aortic walls MFG-E8 protein levels increased while intact TPELN protein levels decreased (Fig. 2A) ${ }^{29,} 31$. Further, dual labelling showed that with age there also an increase in the colocalization of MFGE8 and TPELN (yellow, Fig. 2A). Immunoblotting analyses showed that intact TPELN protein levels decreased by 5-fold (Fig. 2B) while MFG-E8 increased by 6.8-fold (Fig. 2C) in old vs young aortic walls. Similarly, in old VSMCs, MFG-E8 protein expression nearly doubled via immunoblotting analysis when compared to young (Fig. 3A). We also observed that intact TPELN protein levels decreased by greater than $50 \%$ in the old compared to young VSMCs (Fig. 3B).

\section{rhMFG-E8 reduces TPELN protein levels in VSMCs.}

MFG-E8 colocalized with TPELN and may subsequently affect this core elastic fiber protein production and properties. Indeed, treating both young and old VSMCs to a recombinant human MFG-E8 (rhMFG-E8, 100ng/ml) reduced the levels of intact TPELN protein by $47.2 \%$ in young (Fig. 4A) and by $26.8 \%$ in old (Fig.4B), but the abundance of TPELN mRNA was not significantly altered in either young and old cells (Supplemental Fig. I). Importantly, silencing MFG-E8 mRNA were markedly knocked down MFG-E8 protein levels in both young and old VSMCs (Supplemental Fig. II), consequently, intact TPELN protein levels was increased by $63 \%$ in young (Fig. 4C) and by 97\% in old cells (Fig. 4D) while MFG-E8 silencing did not significantly affect TPELN mRNA levels (Supplemental Fig III).

\section{rhMFG-E8 reduces TPELN protein levels via p38 MAPK signaling in VSMCs}

MFG-E8 is an extracellular stress cue and p38 is a potent intracellular stress signaling molecule in VSMCs. Treating both young and old VSMCs with rhMFG-E8 increased the phosphorylation of p38 in a time-dependent manner and reached a peak at 5 min after treatment (Fig. 5A and 5B). Importantly, the reduced levels of intact TPELN protein in VSMCs associated with rhMFG-E8 
treatment was completely prevented by the p38 inhibitor, SB203580, in both young and old cells (Fig. 5C and 5D).

\section{rhMFG-E8 induces MMP-2 activation via p38 MAPK signaling, and activated MMP-2} cleaves TPELN in VSMCs

MMP-2 is not only an intracellular but also an extracellular matrix proteinase. PAGE zymography showed that treating both young and old VSMCs with rhMFG-E8 significantly increased MMP-2 activation by 3.1-fold and 2.1-fold, respectively (Fig. 6A and 6B), and this effect was completely inhibited by SB203580, a p38 inhibitor (Fig. 6C and 6D).

Furthermore, co-immunoprecipitation revealed that MMP-2 protein physically interacted with intact TPELN in young VSMCs and undetected in old cells since intact TPELN was almost completely degraded by activated MMP-2 (Fig. 7A). Indeed, in vitro study showed that exogenous activated MMP-2 effectively cleaved intact TPELN in young VSMCs ( 6.5-fold) (Fig. 7B). Notably, silencing MMP-2 enhanced intact TPELN protein abundance by $25 \%$ in young (Fig. 7C) and by $53 \%$ in old VSMCs (Fig. 7D).

\section{rhMFG-E8 promotes the calcified phenotypic shift of VSMCs via p38 signaling}

SM22 $\alpha$, a well-known early VSMC differentiation protein, and fetuin-A, a potent anti-calcification protein $^{39-42}$, were utilized to predict whether $\mathrm{p} 38$ signaling is involved in the MFG-E8-associated calcified phenotype shift of VSMCs. Treating VSMCs with rhMFG-E8 reduced SM22 $\alpha$ protein levels by $20 \%$ in young (Fig. 8A) and by $40 \%$ in old (Fig. 8B), and this effect was eliminated by the p38 inhibitor, SB203580. Importantly, rhMFG-E8 treatment reduced fetuin-A protein levels by $38 \%$ in both young (Fig. 8A) and similarly by 38\% old VSMCs (Fig. 8B), and this effect was also abolished by the p38 inhibitor. In addition, overexpressing TPELN in cultured VSMCs of old rats significantly increased TPELN levels and simultaneously blocked rh-MFG-E8 induced reduction of fetuin-A levels (Fig. 8C).

\section{MFG-E8 KO retards age-associated aortic elastin degradation and calcification}

The above in vivo and in vitro rat studies suggested that MFG-E8 signaling is involved in ageassociated elastolysis and calcification. Here, young (40-week-old) and old (97-week-old) MFGE8 KO and aged match WT mice further proofed this idea. Histochemical staining of aortic walls harvested from young and old MFG-E8 KO and aged matched WT mice revealed that there were no significantly differences in collagen disposition, elastin degradation, and calcification in young mice (Supplemental Figure IV), but, very importantly, there were striking differences in old mice (Fig 9.). The elastic fiber fraction was decreased by $25 \%$ while collagen deposits and calcification were increased by $52 \%$ and $82 \%$, respectively, in old WT compared to old MFG-E8 KO mice (Fig 9A, B \& C). Western blotting analysis demonstrated that aortic activated MMP-2 protein and activity were markedly increased in old WT vs aged-matched MFG-E8 KO mice (Fig. 9D). Importantly, calcification related alkaline phosphatase (ALP) ${ }^{23,43}$ and runt-related transcription factor 1 (RUNX2) ${ }^{5,56}$ were significantly increased while fetuin-A was significantly decreased in old WT vs. age-matched MFG-E8 KO mice (Fig. 9D). 


\section{Discussion}

The age-associated increases in arterial elastolysis is linked closely to an increase in arterial calcification $^{1-4}$. Maintaining certain levels of intact TPELN is a key to ensuring arterial elastic meshwork integrity and arterial health ${ }^{5,6,13}$. With advancing age, MFG-E8 expression increases while intact TPELN decreases in the arterial wall and VSMCs. At the tissue level, increased MFG-E8 triggers MMP-2 activation, subsequently cleaving TPELN and promoting elastolysis in the aging arterial wall; further, MFG-E8 has a high affinity for cleaved elastin fibers, recruiting calcium-phosphorus products, creating a biomineralization microenvironment, and potentiating calcification in the aging arterial wall. At the cellular level, degraded TPELN peptides or elastin derived peptides or the absence of TPELN potentially shift the differentiated state of VSMCs into the dedifferentiated pro-calcification state ${ }^{12,44,45}$. Thus, interplays of MFG-E8, MMP-2, and TPELN in VSMCs eventually turns the arterial wall into elastolysis and calcification states, which are characteristic features of arterial wall aging (Fig 10).

MFG-E8-associated reduction of intact TPELN levels are mediated by p38 phosphorylation in VSMCs. Phosphorylation of p38 plays an important role in maintaining the integrity of TPELN in various cells in responses to stress ${ }^{46,47}$. Prior studies showed that aging significantly increases phosphorylation of p38 in the arterial wall and VSMCs during stressful conditions $^{21,48}$. Our current study shows that increased p38 phosphorylation simultaneously decreases intact TPELN levels in both young and old VSMCs, and this effect is completely diminished by p38 inhibition. These findings reveal that MFGE8/p38 signaling is a key pathway in maintaining the levels of intact TPELN in VSMCs with aging. We found that neither rhMFGE8 nor si-MFG-E8 impacts upon TPELN mRNA levels, however, they markedly alter the activation of MMP-2 via p38 phosphorylation, suggesting that MFG-E8 significantly decreases intact TPELN protein through post-translational modifications. Prior and current studies show that MMP-2 is a powerful protease involved in the degradation of extracellular matrix, including $\mathrm{TPELN}^{44,}{ }^{49}$. The present findings also demonstrate that MFG-E8 activates MMP-2, and subsequently once activated, MMP-2 noticeably cleaves TPELN in VSMCs; in contrast, MMP-2 silencing significantly increased the levels of TPELN in VSMCs.

The phenotypic shift of differentiated VSMCs state into a dedifferentiated state is a crucial cellular event in adverse arterial remodeling ${ }^{17,20,27,28}$, and is accompanied by the downregulation of intact TPELN with age. SM22 $\alpha$ protein is a differentiation and anti-inflammation molecule of VSMCs; and fetuin A is a potent endogenous inhibitor of calcification of VSMCs or in arterial walls 10, 17, 20,39, 41, 50. Under the MFG-E8 stimulus, both SM22 $\alpha$ and fetuin A abundance are reduced via p38 phosphorylation in VSMCs. MFG-E8 activated MMP-2 is a powerful inflammatory proteinase, which effectively cleaves TPELN in VSMCs. Degraded elastin has a high affinity for calcium-phosphorus products leading to biomineralization in the arterial walls ${ }^{8}$, 15, 16, 51. These findings indicate that MFG-E8-treated VSMCs are altered into a de-differentiated proinflammatory calcified state.

Notably, our current study documents that the knockout of MFG-E8 markedly reduces MMP-2 activity, and ALP and RUNX2 expression while significantly increases fetuin-A expression in the mouse aortic wall. Activated MMP-2 has a high affinity for elastic laminae and 
cleaves these fibers which are susceptible to being calcified ${ }^{52}$. Fetuin-A, also known as alpha-2HS-glycoprotein ${ }^{53}$, is a mineral carrier protein and a systemic inhibitor of pathological mineralization $^{40,54}$. It carries insoluble calcium phosphate forming soluble complexes inhibiting calcium deposition ${ }^{53}$. Loss of fetuin A increases systemic soft tissue calcification in mice ${ }^{40,42}$. Fetuin A decreases with advancing age and promotes an age-associated increase in ectopic calcification $^{40,54}$. Runx 2 is a transcription factor, that enhances the chondro-osseous differentiation of VSMCs, thus promoting calcification and stiffness in the arterial wall ${ }^{55}$. ALP is a non-tissue specific enzyme that is detected in the calcified arterial wall ${ }^{43,53,56}$. ALP also is a dephosphorylating compound, which converts pyrophosphate (soluble) into phosphate (insoluble), facilitating calcium deposition. Thus, MFG-E8 signaling cascade is the molecular foundation of the age-associated arterial calcification

In summary, MFG-E8 signaling phenotypically shifts VSMCs into a proinflammatory calcified state, and eventually accelerates age-associated adverse arterial remodeling, including elastolysis and calcification. Therefore, targeting MFG-E8 signaling is a potential novel molecular therapeutic approach to maintaining arterial health with aging. 
bioRxiv preprint doi: https://doi.org/10.1101/2020.10.05.326728; this version posted October 7, 2020. The copyright holder for this preprint (which was not certified by peer review) is the author/funder. This article is a US Government work. It is not subject to copyright under 17 USC 105 and is also made available for use under a CCO license.

\section{Acknowledgements}

None 
bioRxiv preprint doi: https://doi.org/10.1101/2020.10.05.326728; this version posted October 7, 2020. The copyright holder for this preprint

(which was not certified by peer review) is the author/funder. This article is a US Government work. It is not subject to copyright under 17 USC 105 and is also made available for use under a CCO license.

\section{Sources of Funding}

This research was supported by the Intramural Research Program of the National Institute on Aging, National Institutes of Health. 
bioRxiv preprint doi: https://doi.org/10.1101/2020.10.05.326728; this version posted October 7, 2020. The copyright holder for this preprint (which was not certified by peer review) is the author/funder. This article is a US Government work. It is not subject to copyright under 17 USC 105 and is also made available for use under a CCO license.

\section{Disclosures}

None. 
Table 1. Primary Antibodies

\begin{tabular}{|c|c|c|c|c|}
\hline Antibody & Species & Titer blotting & Titer staining & Source \\
\hline$\beta$-actin & M & $1: 1000$ & & Santa Cruz, CA \\
\hline Fetuin-A & M & $1: 200$ & & Santa Cruz, CA \\
\hline MFG-E8 & $\mathrm{R}$ & $1: 200$ & $1: 50$ & Santa Cruz, CA \\
\hline MMP-2 & $\mathrm{R}$ & $1: 1500$ & & Novusbio, CO \\
\hline p-p38 & $\mathrm{R}$ & $1: 1000$ & & Cell signaling, MA \\
\hline $\mathrm{p}-38$ & $\mathrm{R}$ & $1: 1000$ & & Cell signaling, MA \\
\hline $\operatorname{SM} 22 \alpha$ & $\mathrm{G}$ & $1: 10000$ & & Abcam, MA \\
\hline TPELN & $\mathrm{R}$ & $1: 500$ & $1: 50$ & Abcam, MA \\
\hline
\end{tabular}

$\mathrm{M}=$ mouse, $\mathrm{R}=$ rat, $\mathrm{G}=$ goat. 


\section{References}

1. Wang M, Jiang L, Monticone RE, Lakatta EG. Proinflammation: The key to arterial aging. Trends Endocrinol Metab. 2014;25:72-79

2. Wang M, Monticone RE, McGraw KR. Proinflammatory arterial stiffness syndrome: A signature of large arterial aging. J Vasc Res. 2018;55:210-223

3. Wang M, Monticone RE, Lakatta EG. Arterial aging: A journey into subclinical arterial disease. Curr Opin Nephrol Hypertens. 2010;19:201-207

4. Wahart A, Hocine T, Albrecht C, Henry A, Sarazin T, Martiny L, El Btaouri H, Maurice $P$, Bennasroune A, Romier-Crouzet B, Blaise S, Duca L. Role of elastin peptides and elastin receptor complex in metabolic and cardiovascular diseases. FEBS J. 2019;286:2980-2993

5. Fhayli W, Boyer M, Ghandour Z, Jacob MP, Andrieu JP, Starcher BC, Esteve E, Faury G. Chronic administration of minoxidil protects elastic fibers and stimulates their neosynthesis with improvement of the aorta mechanics in mice. Cell Signal. 2019;62:109333

6. Coquand-Gandit M, Jacob MP, Fhayli W, Romero B, Georgieva M, Bouillot S, Esteve E, Andrieu JP, Brasseur S, Bouyon S, Garcia-Honduvilla N, Huber P, Bujan J, Atanasova M, Faury G. Chronic treatment with minoxidil induces elastic fiber neosynthesis and functional improvement in the aorta of aged mice. Rejuvenation Res. 2017;20:218-230

7. Fhayli W, Boete $Q$, Harki O, Briancon-Marjollet A, Jacob MP, Faury G. Rise and fall of elastic fibers from development to aging. Consequences on arterial structure-function and therapeutical perspectives. Matrix Biol. 2019;84:41-56

8. Duca L, Blaise S, Romier B, Laffargue M, Gayral S, El Btaouri H, Kawecki C, Guillot A, Martiny L, Debelle $L$, Maurice $P$. Matrix ageing and vascular impacts: Focus on elastin fragmentation. Cardiovasc Res. 2016;110:298-308

9. Wang M, Zhang J, Telljohann R, Jiang L, Wu J, Monticone RE, Kapoor K, Talan M, Lakatta EG. Chronic matrix metalloproteinase inhibition retards age-associated arterial proinflammation and increase in blood pressure. Hypertension. 2012;60:459-466

10. Wang M, Zhang L, Zhu W, Zhang J, Kim SH, Wang Y, Ni L, Telljohann R, Monticone RE, McGraw K, Liu L, de Cabo R, Lakatta EG. Calorie restriction curbs proinflammation that accompanies arterial aging, preserving a youthful phenotype. J Am Heart Assoc. 2018;7:e009112

11. Van Doren SR. Matrix metalloproteinase interactions with collagen and elastin. Matrix Biol. 2015;44-46:224-231

12. Sugiura T, Agarwal R, Tara S, Yi T, Lee YU, Breuer CK, Weiss AS, Shinoka T. Tropoelastin inhibits intimal hyperplasia of mouse bioresorbable arterial vascular grafts. Acta Biomater. 2017;52:7480

13. Fhayli W, Boete $Q$, Kihal N, Cenizo V, Sommer P, Boyle WA, Jacob MP, Faury G. Dill extract induces elastic fiber neosynthesis and functional improvement in the ascending aorta of aged mice with reversal of age-dependent cardiac hypertrophy and involvement of lysyl oxidase-like1. Biomolecules. 2020;10

14. Treharne GD, Boyle JR, Goodall S, Loftus IM, Bell PR, Thompson MM. Marimastat inhibits elastin degradation and matrix metalloproteinase 2 activity in a model of aneurysm disease. Br J Surg. 1999;86:1053-1058

15. Urry DW. Neutral sites for calcium ion binding to elastin and collagen: A charge neutralization theory for calcification and its relationship to atherosclerosis. Proc Natl Acad Sci U S A. 1971;68:810-814 
16. Gourgas O, Muiznieks LD, Bello DG, Nanci A, Sharpe S, Cerruti M. Cross-linked elastin-like polypeptide membranes as a model for medial arterial calcification. Biomacromolecules. 2019;20:2625-2636

17. Ailawadi G, Moehle CW, Pei H, Walton SP, Yang Z, Kron IL, Lau CL, Owens GK. Smooth muscle phenotypic modulation is an early event in aortic aneurysms. J Thorac Cardiovasc Surg. 2009;138:1392-1399

18. Ellis PD, Chen Q, Barker PJ, Metcalfe JC, Kemp PR. Nov gene encodes adhesion factor for vascular smooth muscle cells and is dynamically regulated in response to vascular injury. Arterioscler Thromb Vasc Biol. 2000;20:1912-1919

19. Dai X, Thiagarajan D, Fang J, Shen J, Annam NP, Yang Z, Jiang H, Ju D, Xie Y, Zhang K, Tseng YY, Yang Z, Rishi AK, Li HJ, Yang M, Li L. Sm22alpha suppresses cytokine-induced inflammation and the transcription of nf-kappab inducing kinase (nik) by modulating srf transcriptional activity in vascular smooth muscle cells. PLoS One. 2017;12:e0190191

20. Martin-Pardillos A, Sorribas V. Effects of donor age and proliferative aging on the phenotype stability of rat aortic smooth muscle cells. Physiol Rep. 2015;3

21. Li M, Mossman BT, Kolpa E, Timblin CR, Shukla A, Taatjes DJ, Fukagawa NK. Age-related differences in map kinase activity in vsmc in response to glucose or tnf-alpha. J Cell Physiol. 2003;197:418-425

22. Liu X, Huang X, Chen L, Zhang Y, Li M, Wang L, Ge C, Wang H, Zhang M. Mechanical stretch promotes matrix metalloproteinase-2 and prolyl-4-hydroxylase alpha1 production in human aortic smooth muscle cells via akt-p38 mapk-jnk signaling. Int J Biochem Cell Biol. 2015;62:15-23

23. Simmons CA, Nikolovski J, Thornton AJ, Matlis S, Mooney DJ. Mechanical stimulation and mitogen-activated protein kinase signaling independently regulate osteogenic differentiation and mineralization by calcifying vascular cells. J Biomech. 2004;37:1531-1541

24. Wu J, Thabet SR, Kirabo A, Trott DW, Saleh MA, Xiao L, Madhur MS, Chen W, Harrison DG. Inflammation and mechanical stretch promote aortic stiffening in hypertension through activation of p38 mitogen-activated protein kinase. Circ Res. 2014;114:616-625

25. Yang Y, Sun Y, Chen J, Bradley WE, Dell'Italia LJ, Wu H, Chen Y. Akt-independent activation of p38 map kinase promotes vascular calcification. Redox Biol. 2018;16:97-103

26. Castello L, Froio T, Cavallini G, Biasi F, Sapino A, Leonarduzzi G, Bergamini E, Poli G, Chiarpotto E. Calorie restriction protects against age-related rat aorta sclerosis. FASEB J. 2005;19:1863-1865

27. Krohn JB, Hutcheson JD, Martinez-Martinez E, Irvin WS, Bouten CV, Bertazzo S, Bendeck MP, Aikawa E. Discoidin domain receptor-1 regulates calcific extracellular vesicle release in vascular smooth muscle cell fibrocalcific response via transforming growth factor-beta signaling. Arterioscler Thromb Vasc Biol. 2016;36:525-533

28. Chiang HY, Chu PH, Lee TH. Mfg-e8 mediates arterial aging by promoting the proinflammatory phenotype of vascular smooth muscle cells. J Biomed Sci. 2019;26:61

29. Wang M, Fu Z, Wu J, Zhang J, Jiang L, Khazan B, Telljohann R, Zhao M, Krug AW, Pikilidou M, Monticone RE, Wersto R, Van Eyk J, Lakatta EG. Mfg-e8 activates proliferation of vascular smooth muscle cells via integrin signaling. Aging Cell. 2012;11:500-508

30. Wang $\mathrm{M}$, Wang $\mathrm{HH}$, Lakatta EG. Milk fat globule epidermal growth factor viii signaling in arterial wall remodeling. Curr Vasc Pharmacol. 2013;11:768-776

31. Fu Z, Wang M, Gucek M, Zhang J, Wu J, Jiang L, Monticone RE, Khazan B, Telljohann R, Mattison J, Sheng S, Cole RN, Spinetti G, Pintus G, Liu L, Kolodgie FD, Virmani R, Spurgeon H, Ingram DK, Everett AD, Lakatta EG, Van Eyk JE. Milk fat globule protein epidermal growth factor-8: A pivotal relay element within the angiotensin ii and monocyte chemoattractant protein-1 signaling cascade mediating vascular smooth muscle cells invasion. Circ Res. 2009;104:1337-1346 
32. Marie P, Labas V, Brionne A, Harichaux G, Hennequet-Antier C, Nys Y, Gautron J. Quantitative proteomics and bioinformatic analysis provide new insight into protein function during avian eggshell biomineralization. J Proteomics. 2015;113:178-193

33. Marie P, Labas V, Brionne A, Harichaux G, Hennequet-Antier C, Rodriguez-Navarro AB, Nys Y, Gautron J. Quantitative proteomics provides new insights into chicken eggshell matrix protein functions during the primary events of mineralisation and the active calcification phase. $J$ Proteomics. 2015;126:140-154

34. Stapane L, Le Roy N, Hincke MT, Gautron J. The glycoproteins edil3 and mfge8 regulate vesicle mediated eggshell calcification in a new model for avian biomineralisation. J Biol Chem. 2019

35. Wang $\mathrm{M}$, Lakatta EG. Altered regulation of matrix metalloproteinase-2 in aortic remodeling during aging. Hypertension. 2002;39:865-873

36. Wang $M$, Zhang J, Spinetti $G$, Jiang LQ, Monticone R, Zhao D, Cheng L, Krawczyk M, Talan M, Pintus G, Lakatta EG. Angiotensin ii activates matrix metalloproteinase type ii and mimics ageassociated carotid arterial remodeling in young rats. Am J Pathol. 2005;167:1429-1442

37. Motegi S, Leitner WW, Lu M, Tada Y, Sardy M, Wu C, Chavakis T, Udey MC. Pericyte-derived mfg-e8 regulates pathologic angiogenesis. Arterioscler Thromb Vasc Biol. 2011;31:2024-2034

38. Neutzner M, Lopez T, Feng X, Bergmann-Leitner ES, Leitner WW, Udey MC. Mfg-e8/lactadherin promotes tumor growth in an angiogenesis-dependent transgenic mouse model of multistage carcinogenesis. Cancer Res. 2007;67:6777-6785

39. Back M, Aranyi T, Cancela ML, Carracedo M, Conceicao N, Leftheriotis G, Macrae V, Martin L, Nitschke Y, Pasch A, Quaglino D, Rutsch F, Shanahan C, Sorribas V, Szeri F, Valdivielso P, Vanakker $\mathrm{O}, \mathrm{Kempf} \mathrm{H}$. Endogenous calcification inhibitors in the prevention of vascular calcification: A consensus statement from the cost action eurosoftcalcnet. Front Cardiovasc Med. 2018;5:196

40. Jahnen-Dechent W, Heiss A, Schafer C, Ketteler M. Fetuin-a regulation of calcified matrix metabolism. Circ Res. 2011;108:1494-1509

41. Mutluay R, Konca Degertekin C, Isiktas Sayilar E, Derici U, Gultekin S, Gonen S, Arinsoy ST, Sindel MS. Serum fetuin-a is associated with the components of miac(malnutrition, inflammation, atherosclerosis, calcification) syndrome in different stages of chronic kidney disease. Turk J Med Sci. 2019;49:327-335

42. Westenfeld R, Schafer C, Kruger T, Haarmann C, Schurgers LJ, Reutelingsperger C, Ivanovski O, Drueke T, Massy ZA, Ketteler M, Floege J, Jahnen-Dechent W. Fetuin-a protects against atherosclerotic calcification in ckd. J Am Soc Nephrol. 2009;20:1264-1274

43. Tani T, Fujiwara M, Orimo H, Shimizu A, Narisawa S, Pinkerton AB, Millan JL, Tsuruoka S. Inhibition of tissue-nonspecific alkaline phosphatase protects against medial arterial calcification and improves survival probability in the ckd-mbd mouse model. J Pathol. 2020;250:30-41

44. Heinz A, Jung MC, Duca L, Sippl W, Taddese S, Ihling C, Rusciani A, Jahreis G, Weiss AS, Neubert $\mathrm{RH}$, Schmelzer CE. Degradation of tropoelastin by matrix metalloproteinases--cleavage site specificities and release of matrikines. FEBS J. 2010;277:1939-1956

45. Lin CJ, Staiculescu MC, Hawes JZ, Cocciolone AJ, Hunkins BM, Roth RA, Lin CY, Mecham RP, Wagenseil JE. Heterogeneous cellular contributions to elastic laminae formation in arterial wall development. Circ Res. 2019;125:1006-1018

46. Choi WS, Mitsumoto A, Kochevar IE. Involvement of reactive oxygen species in tgf-beta1induced tropoelastin expression by human dermal fibroblasts. Photochem Photobiol. 2009;85:1425-1433

47. Ortega R, Collado A, Selles F, Gonzalez-Navarro H, Sanz MJ, Real JT, Piqueras L. Sglt-2 (sodiumglucose cotransporter 2 ) inhibition reduces ang ii (angiotensin ii)-induced dissecting abdominal 
aortic aneurysm in apoe (apolipoprotein e) knockout mice. Arterioscler Thromb Vasc Biol. 2019;39:1614-1628

48. Wu Z, Yu Y, Liu C, Xiong Y, Montani JP, Yang Z, Ming XF. Role of p38 mitogen-activated protein kinase in vascular endothelial aging: Interaction with arginase-ii and s6k1 signaling pathway. Aging (Albany NY). 2015;7:70-81

49. Castro MM, Tanus-Santos JE. Inhibition of matrix metalloproteinases (mmps) as a potential strategy to ameliorate hypertension-induced cardiovascular alterations. Curr Drug Targets. 2013;14:335-343

50. Kapustin AN, Chatrou ML, Drozdov I, Zheng Y, Davidson SM, Soong D, Furmanik M, Sanchis P, De Rosales RT, Alvarez-Hernandez D, Shroff R, Yin X, Muller K, Skepper JN, Mayr M, Reutelingsperger CP, Chester A, Bertazzo S, Schurgers $\mathrm{L}$, Shanahan CM. Vascular smooth muscle cell calcification is mediated by regulated exosome secretion. Circ Res. 2015;116:1312-1323

51. Jiang L, Zhang J, Monticone RE, Telljohann R, Wu J, Wang M, Lakatta EG. Calpain-1 regulation of matrix metalloproteinase 2 activity in vascular smooth muscle cells facilitates age-associated aortic wall calcification and fibrosis. Hypertension. 2012;60:1192-1199

52. Wang M, Zhao D, Spinetti G, Zhang J, Jiang L-Q, Pintus G, Monticone R, Lakatta EG. Matrix metalloproteinase 2 activation of transforming growth factor- $\beta 1$ (tgf- $\beta 1$ ) and tgf- $\beta 1$-type ii receptor signaling within the aged arterial wall. Arteriosclerosis, thrombosis, and vascular biology. 2006;26:1503-1509

53. Villa-Bellosta R. New insights into endogenous mechanisms of protection against arterial calcification. Atherosclerosis. 2020

54. Robinson KN, Teran-Garcia M. From infancy to aging: Biological and behavioral modifiers of fetuin-a. Biochimie. 2016;124:141-149

55. Johnson KA, Polewski M, Terkeltaub RA. Transglutaminase 2 is central to induction of the arterial calcification program by smooth muscle cells. Circ Res. 2008;102:529-537

56. Pustlauk W, Westhoff TH, Claeys L, Roch T, Geissler S, Babel N. Induced osteogenic differentiation of human smooth muscle cells as a model of vascular calcification. Sci Rep. 2020;10:5951 


\section{Highlights}

- $\quad$ MFG-E8 increases in aged aortic wall or VSMCs; in contrast, TPELN protein levels decrease,

- Treating VSMCs with rhMFG-E8 protein significantly reduces intact TPLEN, SM22 $\alpha$, and Fetuin-A protein levels while increases MMP-2 activation. All these effects are inhibited by the blockade of p38 mitogen-activated protein kinase phosphorylation.

- Activated MMP-2 effectively cleaves intact TPLEN in VSMCs.

- MFG-E8 KO retards the age-associated increases in MMP-2 activation, elastolysis, and calcification in the aortic walls of mice.

- Thus, MFG-E8 is a potential novel molecule to diminish or prevent ageassociated arterial elastolysis and calcification. 


\section{Figure legends}

Figure 1. Aortic remodeling and calcification with aging. A. Representative photomicrographs of cross-sectional view of aortic wall stained with E.V.G (dark color). B. Average data of macroelastin laminae breaks shown as mean $\pm \operatorname{SEM}\left(\mathrm{n}=4\right.$ rats/group). $T$-test, ${ }^{*} \mathrm{p}<0.05$. C. Representative photomicrographs of en face view of aortic medial wall stained with E.V.G (dark color). D. Average data of micro-elastin fiber fraction shown as mean \pm SEM ( $n=3$ rats/group,). $T$-test, $* \mathrm{p}<0.05$. E. Representative photomicrographs of en face view of aortic medial wall stained with Masson's trichrome (muscle, red color; extracellular matrix-collagen, blue color). F. Average data of extracellular matrix-collagen fraction shown as mean \pm SEM ( $n=3$ rats/group). $T$-test, ${ }^{*} \mathrm{p}<0.05$. G. Representative photomicrographs of en face view of aortic medial wall stained with Alizarin red (calcium deposits, red color). H. Average data of calcium deposition shown as mean \pm SEM ( $\mathrm{n}=3$ rats/group). $T$-test, $* \mathrm{p}<0.05$. I. Representative photomicrographs of en face view of aortic medial wall stained with Von Kossa (phosphorylate calcium deposits, dark color). J. Average data of phosphorylate calcium deposition shown as mean \pm SEM ( $n=3$ rats/group). $T$-test, $* \mathrm{p}<0.05$. L, lumen; M, medium. Bar $=100 \mu \mathrm{m}$.

Figure 2. MFG-E8 and TPELN expression in aging aortas. A. Representative photomicrographs of en face view of aortic medial wall stained with TPELN (green color) and MFG-E8 (red color) as well as merge (yellow color) in young (upper panels) old (lower panels). Nuclei were counter-stained with DAPI (blue color). Bar $=100 \mu \mathrm{m}$. B. Representative immunoblotting of TPELN in young and old rat aortas. Average data of TPELN (right panel) shown as mean \pm SEM ( $n=4$ rats/group). $T$-test, $* * p<0.01$. C. Representative immunoblotting of MFG-E8 in young and old rat aortas. Average data of MFG-E8 (right panel) shown as mean \pm SEM ( $\mathrm{n}=3$ rats/group). $T$-test, $* \mathrm{p}<0.05$.

Figure 3. MFG-E8 and TPELN expression in aging VSMCs. A. Representative immunoblotting of intact TPELN (parental band) of young and old VSMCs. Average data of intact TPELN protein band shown as mean \pm SEM ( $n=3$ independent experiments from $n=3$ rats/group). $T$-test, $* * \mathrm{p}<0.01$. B. Representative immunoblotting of MFG-E8 in young and old rat VSMCs. Average data of MFG-E8 shown as mean \pm SEM ( $n=3$ independent experiments from $n=3$ rats/group). $T$-test, ${ }^{*} \mathrm{p}<0.05$.

Figure 4. MFG-E8 effects on intact TPELN protein levels in aging VSMCs. A. Young VSMCs were treated for 48 hours in medium containing recombinant human MFG-E8 (rhMFG-E8, 100ng/ml). Representative immunoblotting (left panel) of intact TPELN in young VSMCs treated with or without rhMFG-E8 (100ng/ml) Average data (right panel) shown as mean \pm SEM ( $\mathrm{n}=3$ independent experiments from $\mathrm{n}=3$ rats/group). $T$-test, ${ }^{*} \mathrm{p}<<0.01$. B. Old VSMCs were treated for 48 hours in medium containing recombinant human MFG-E8 (rhMFG-E8, 100ng/ml). Representative immunoblotting (left panel) of intact TPELN in young VSMCs treated with or without rhMFG-E8 (100ng/ml) Average data (right panel) shown as mean \pm SEM ( $\mathrm{n}=3$ independent experiments from $\mathrm{n}=3$ rats/group). $T$-test, $* * \mathrm{p}<0.01$. C. Young VSMCs were transfected for 48 hours with scrambled si-RNA (20nM) (si-NTC) or si-MFG-E8 (20nM). Representative immunoblotting (left panel) of intact TPELN and MFG-E8 of homogenous lysates 
from young VSMCs with siRNA treatment. Average data of intact TPELN levels (right panel) shown as mean \pm SEM ( $n=3$ independent experiments from $n=3$ rats/group). D. Old VSMCs were transfected for 48 hours with scrambled si-RNA (20nM) (si-NTC) or si-MFG-E8 (20nM). Representative immunoblotting (left panel) of intact TPELN and MFG-E8 of homogenous lysates from old VSMCs with siRNA treatment. Average data of intact TPELN levels (right panel) shown as mean $\pm \operatorname{SEM}(n=3$ independent experiments from $n=3$ rats/group).

Figure 5. MFG-E8 regulates TPELN expression through p38 in aging VSMCs. A. Representative immunoblotting for p-p38 and total p38 in young VSMCs. Young cells were treated with or without rh MFG-E8 (100ng/ml) for 0, 5, 10, 30, 60, $120 \mathrm{~min}, 24,48 \mathrm{~h}$ minutes. Average data of p-p38 at $5 \mathrm{~min} . T$-test, $* * \mathrm{p}<0.01 \mathrm{~B}$. Representative immunoblotting for p-p38 and total p38 in old VSMCs. Old cells were treated with or without rh MFG-E8 $(100 \mathrm{ng} / \mathrm{ml})$ for 0, 5 , 10, 30, 60, $120 \mathrm{~min}, 24,48 \mathrm{~h}$ minutes. Average data of p-p38 at $5 \mathrm{~min}$. $T$-test, $* * \mathrm{p}<0.01$. C. Representative immunoblotting (left panel) of TPELN in young VSMCs. Cells were pre-treated with or without SB203580 (20uM) for 1 hour and were then treated with or without rhMFG-E8 $(100 \mathrm{ng} / \mathrm{ml})$ for 24 hours. Average data (right panel) shown as mean \pm SEM $(\mathrm{n}=3$ independent experiments from $n=3$ rats/group). One-way ANOVA followed by Bonferroni post-hoc test, $*_{p}<0.05$ and $* * p<0.01$. D. Representative immunoblotting (left panel) of TPELN in old VSMCs. Cells were pre-treated with or without SB203580 (20uM) for 1 hour and were then treated with or without rhMFG-E8 (100ng/ml) for 24 hours. Average data (right panel) shown as mean \pm SEM ( $\mathrm{n}=3$ independent experiments from $\mathrm{n}=3$ rats/group). One-way ANOVA followed by Bonferroni post-hoc test, $* \mathrm{p}<0.05$ and $* * \mathrm{p}<0.01$.

Figure 6. MFG-E8 regulates TPELN expression through p38 signaling/MMP-2 activation in aging VSMCs. A. Representative zymogram of the medium from young VSMCs treated with or without rhMFG-E8 for 24 hours (100ng/ml) (upper panel). Average data (lower panel) shown as mean \pm SEM ( $n=4$ independent experiments from $n=4$ rats/group). $T$-test, $*_{p}<0.05$. B. Representative zymogram of the medium from old VSMCs treated with or without rhMFG-E8 for 24 hours (100ng/ml) (upper panel). Average data (lower panel) shown as mean \pm SEM ( $\mathrm{n}=4$ independent experiments from $n=4$ rats/group). $T$-test, ${ }^{*} \mathrm{p}<0.05$. C. Representative zymogram of the medium from young VSMCs treated with or without rhMFG-E8 or SB203580 (upper panel). Cells were pre-treated for 1-hour with or without SB203580 (20uM), and then treated for 24 hours with or without rhMFG-E8 $(100 \mathrm{ng} / \mathrm{ml})$. Average data (lower panel) shown as mean $\pm \mathrm{SEM}$ ( $\mathrm{n}=3$ independent experiments from $n=3$ rats/group). One-way ANOVA followed by Bonferroni posthoc test, ${ }^{*} \mathrm{p}<0.01$. D. Representative zymogram of the medium from old VSMCs treated with or without rhMFG-E8 or SB203580 (upper panel). Cells were pre-treated for 1-hour with or without SB203580 $(20 \mathrm{uM})$, and then treated for 24 hours with or without rhMFG-E8 (100ng/ml). Average data (lower panel) shown as mean \pm SEM ( $n=3$ independent experiments from $n=3$ rats/group). One-way ANOVA followed by Bonferroni post-hoc test, ${ }^{*} \mathrm{p}<0.05$.

Figure 7. MMP-2 physically interacts with TPELN and degrades TPELN of VSMCs with aging. A. Representative TPELN immunoblotting of MMP-2 immunoprecipitants from young and old VSMC cell lysates. B. Representative immunoblotting (left panel) of young VSMC cell lysates. Cells were treated with or without activated MMP-2 for 4 hours at $37^{\circ} \mathrm{C}$. Average data (right panel) shown as mean \pm SEM ( $n=3$ independent experiments from $n=3$ rats/group). T-test, ${ }^{*} p<0.05$. C. Representative immunoblotting (left panel) of TPELN and MMP-2 from young VSMC cell lysates 
treated with si-NTC (20 nM) or si- MMP-2 (20nM). Average data of TPELN (right panel) shown as mean \pm SEM $(n=3$ independent experiments from $n=3$ rats/group). $T$-test, $* p<0.05$. D. Representative immunoblotting (left panel) of TPELN and MMP-2 from old VSMC cell lysates treated with si-NTC (20 nM) or si- MMP-2 (20nM). Average data of TPELN (right panel) shown as mean $\pm \operatorname{SEM}\left(\mathrm{n}=3\right.$ independent experiments from $\mathrm{n}=3$ rats/group). $T$-test, ${ }^{*} \mathrm{p}<0.05$.

Figure 8. MFG-E8 signaling shifts the differentiated state into the de-differentiated procalcification state of VSMCs. A. Representative immunoblotting for SM22 $\alpha$ and fetuin-A in young VSMCs (left panel). Young cells were pre-treated with or without SB203580 (20uM) for 1 hour and then treated with or without rhMFG-E8 $(100 \mathrm{ng} / \mathrm{ml})$ for 2 hours. Average data (right panel) shown as mean \pm SEM ( $n=3$ independent experiments from $n=3$ rats/group). One-way ANOVA followed by Bonferroni post-hoc test, ${ }^{*} \mathrm{p}<0.05$. B. Representative immunoblotting for SM22 $\alpha$ and fetuin-A in Old VSMCs (left panel). Old cells were pre-treated with or without SB203580 (20uM) for 1 hour and then treated with or without rhMFG-E8 $(100 \mathrm{ng} / \mathrm{ml})$ for 2 hours. Average data (right panel) shown as mean \pm SEM ( $n=3$ independent experiments from $n=3$ rats/group). One-way ANOVA followed by Bonferroni post-hoc test, ${ }^{*} p<0.05$; and $* * p<0.01$. C. Representative immunoblotting for fetuin-A in old VSMCs (left panel). Cells were pre-transfected with or without pCMV-TPELN (20nM) for 24 hours and then treated with or without rhMFG-E8 (100ng/ml) for 2 hours. Data (right panel) shown as mean \pm SEM $(n=3$ independent experiments from $n=3$ rats/group). One-way ANOVA followed by Bonferroni post-hoc test, ${ }^{*} \mathrm{p}<0.05$ and $* * \mathrm{p}<0.01$.

Figure 9. MFG-E8 KO retards arterial elastolysis and calcification in old mice. A. Representative photomicrographs of cross-sectional view of aortic medial wall stained with Masson's trichrome (muscle, red color; extracellular matrix, blue color). Average data of extracellular matrix fraction (right panel) shown as mean $\pm \mathrm{SEM}$ ( $\mathrm{n}=4$ mice/group). $T$-test, ${ }^{*} \mathrm{p}<0.05$. B. Representative photomicrographs of cross-sectional view of aortic wall stained with E.V.G (dark color). Average data of macro-elastin fraction (right panel) shown as mean \pm SEM ( $n=4$ mice/group). $T$-test, $* * * p<0.001$. C. Representative photomicrographs of cross-sectional view of aortic medial wall stained with Alizarin red (calcium deposits, red color). Average data of calcium deposition (right panel) shown as mean \pm SEM ( $\mathrm{n}=4$ mice/group). $T$-test, $* * * \mathrm{p}<0.001$. L, lumen; M, medium. Bar $=100 \mu \mathrm{m}$. D. Western blots and PAGE zymogram of homogenous aortic protein for MMP-2, ALP, RUNX2, and Fetuin A from old MFG-E8 and age matched WT mice. Average data of MMP-2, ALP, RUNX2, and Fetuin A shown as mean \pm SEM (n=4-5 mice/group). T-test, $* \mathrm{p}<0.05 ; * * * \mathrm{p}<0.001$.

Figure 10. MFG-E8/p38/MMP-2/TPELN signaling cascade in aging VSMCs and arterial walls. 

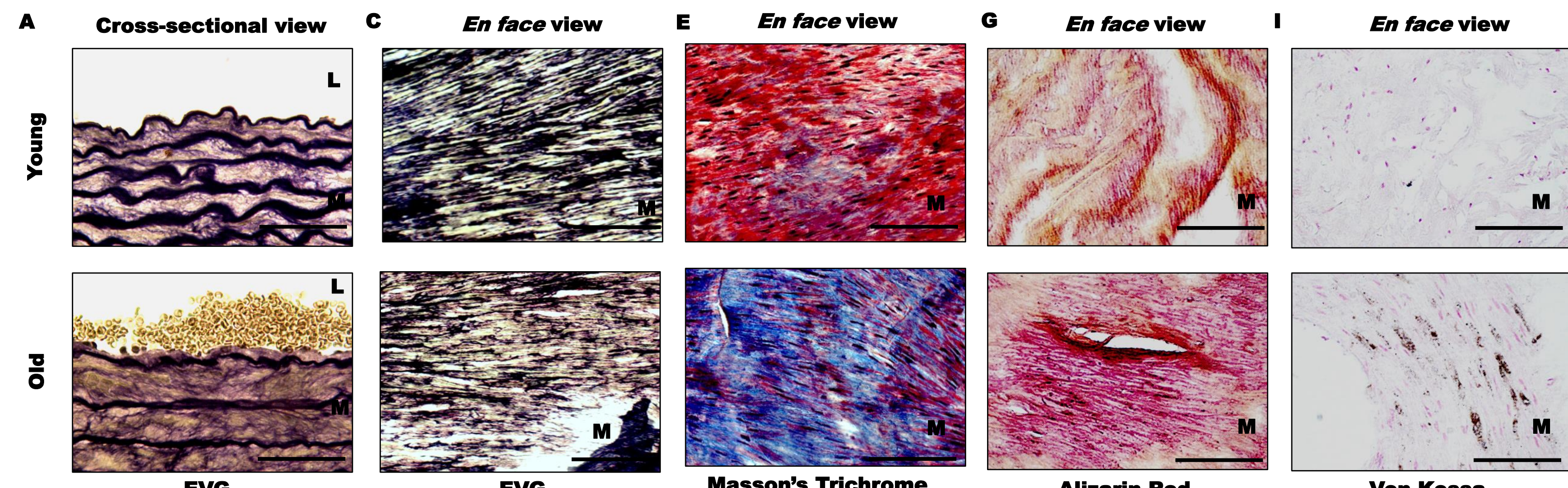
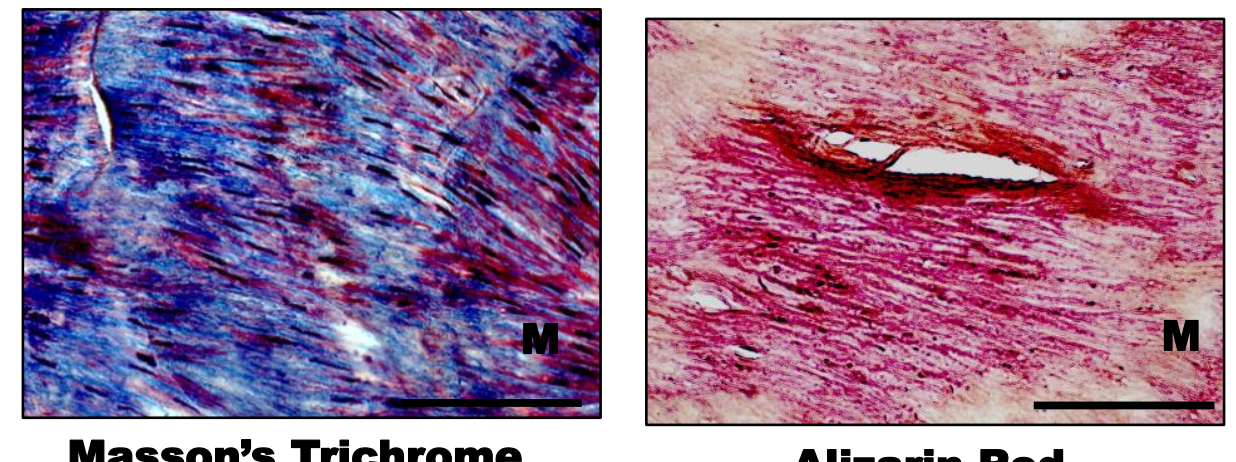

Alizarin Red

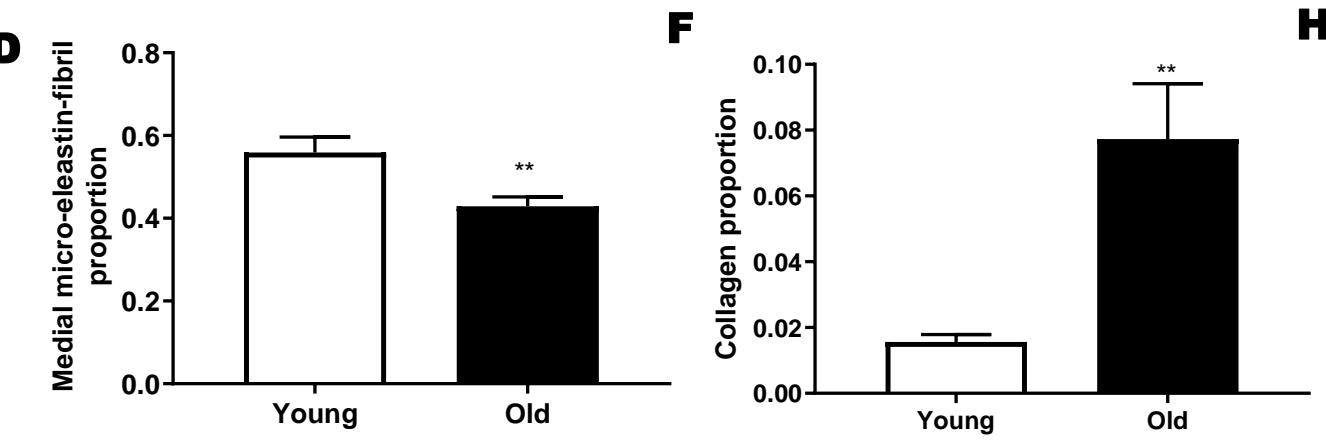

H

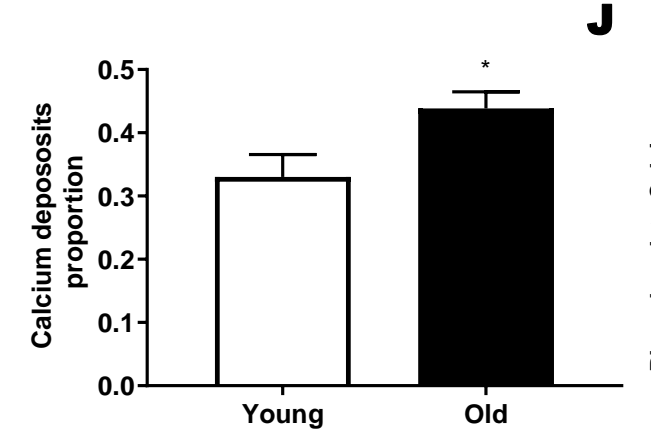

J

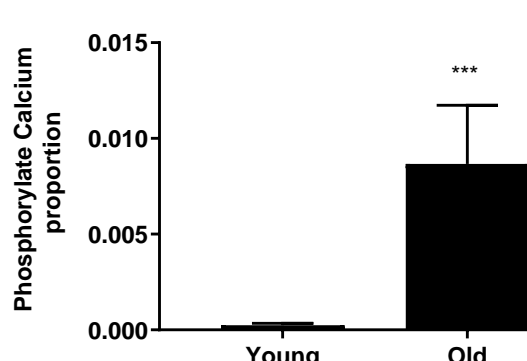



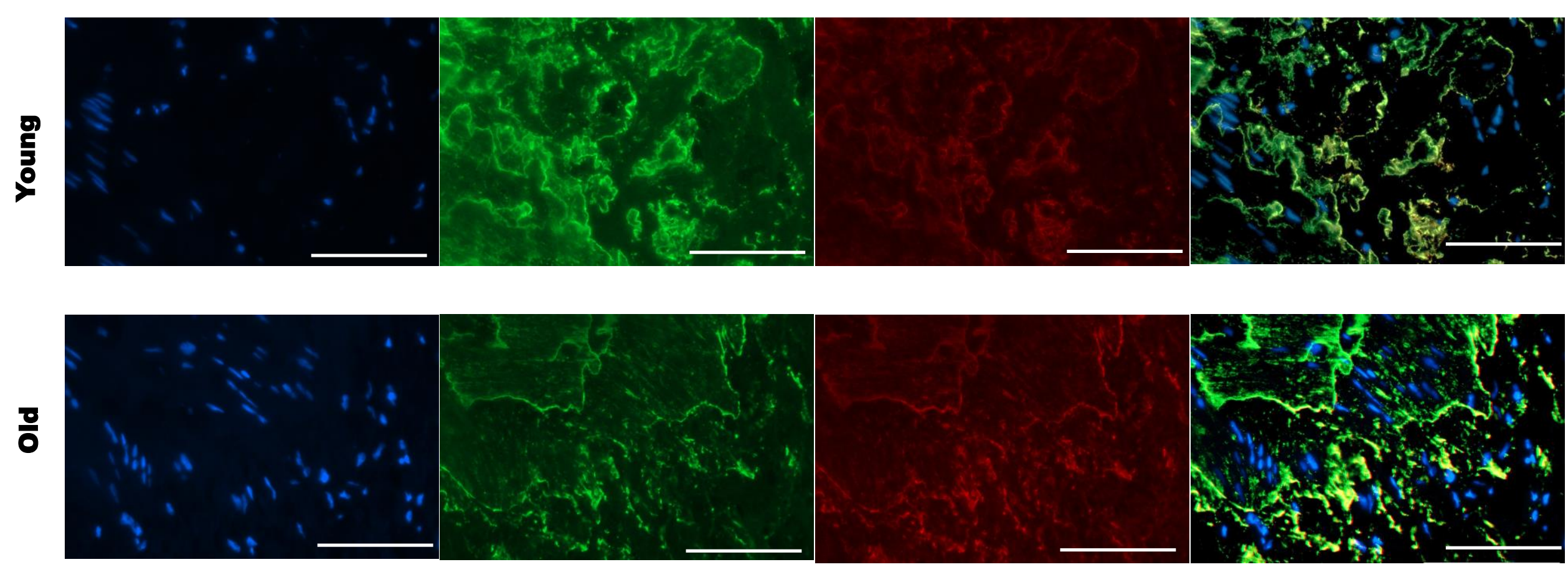

B

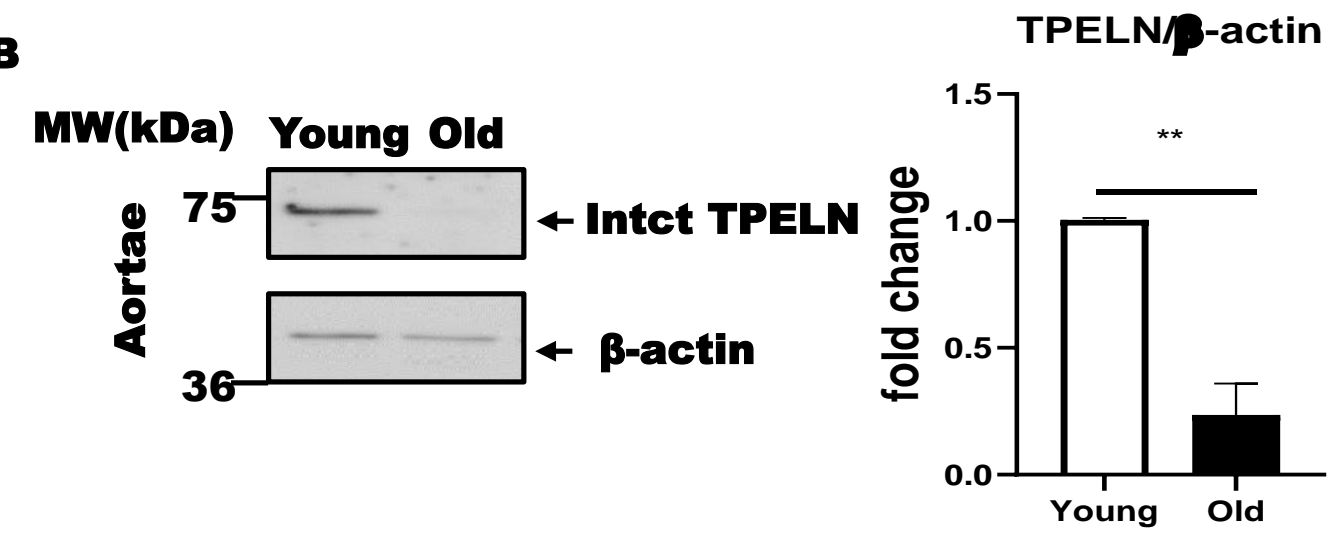

C

MFG-E8/p-actin

MW(kDa) Young Old
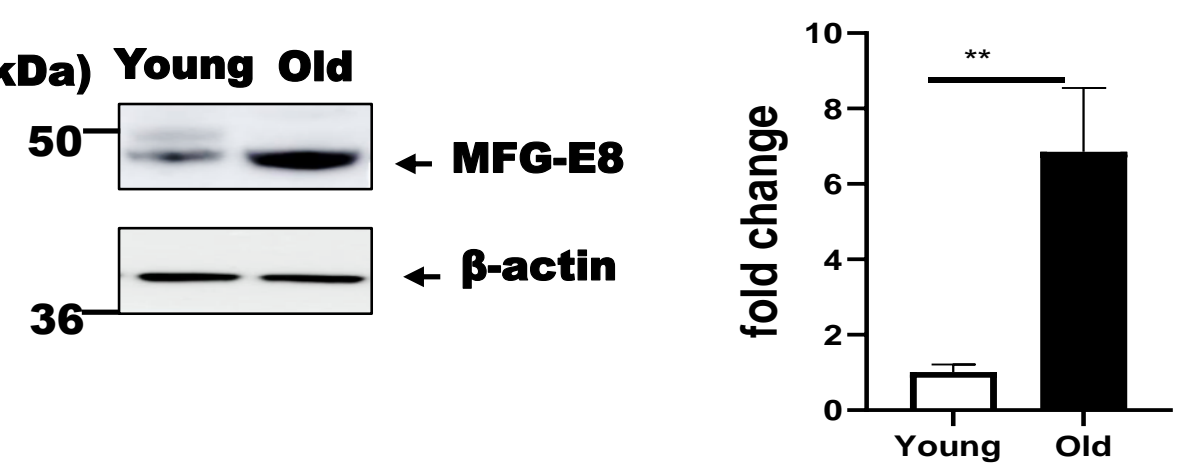

Figure 2 
A

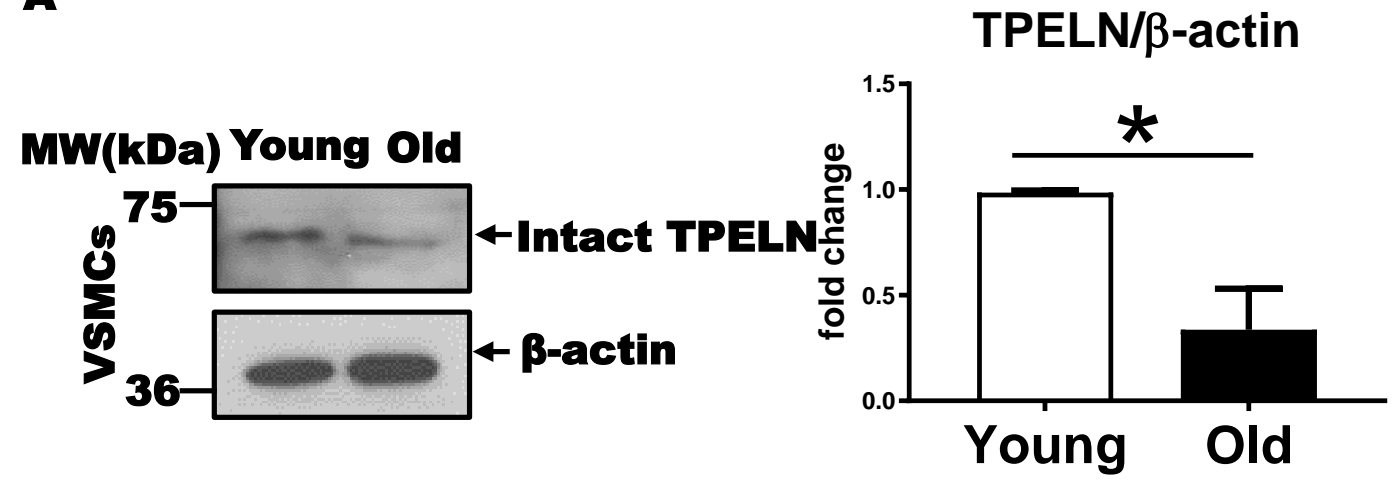

B

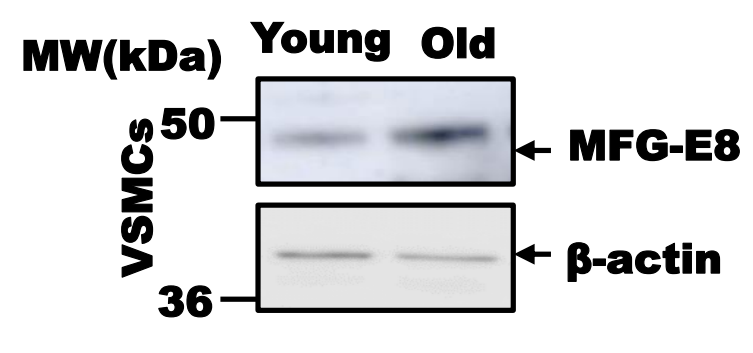

MFG-E8/ $\beta$-actin

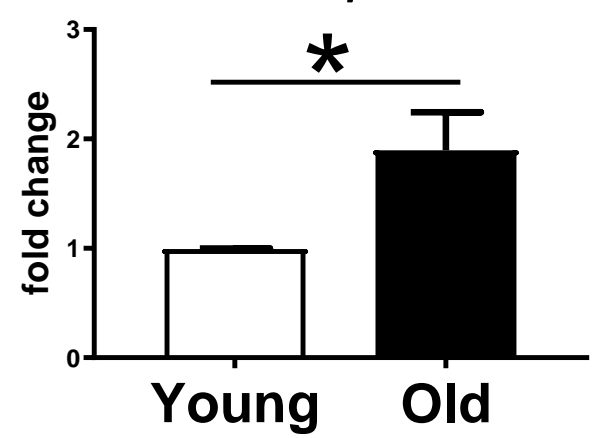

Figure 3 

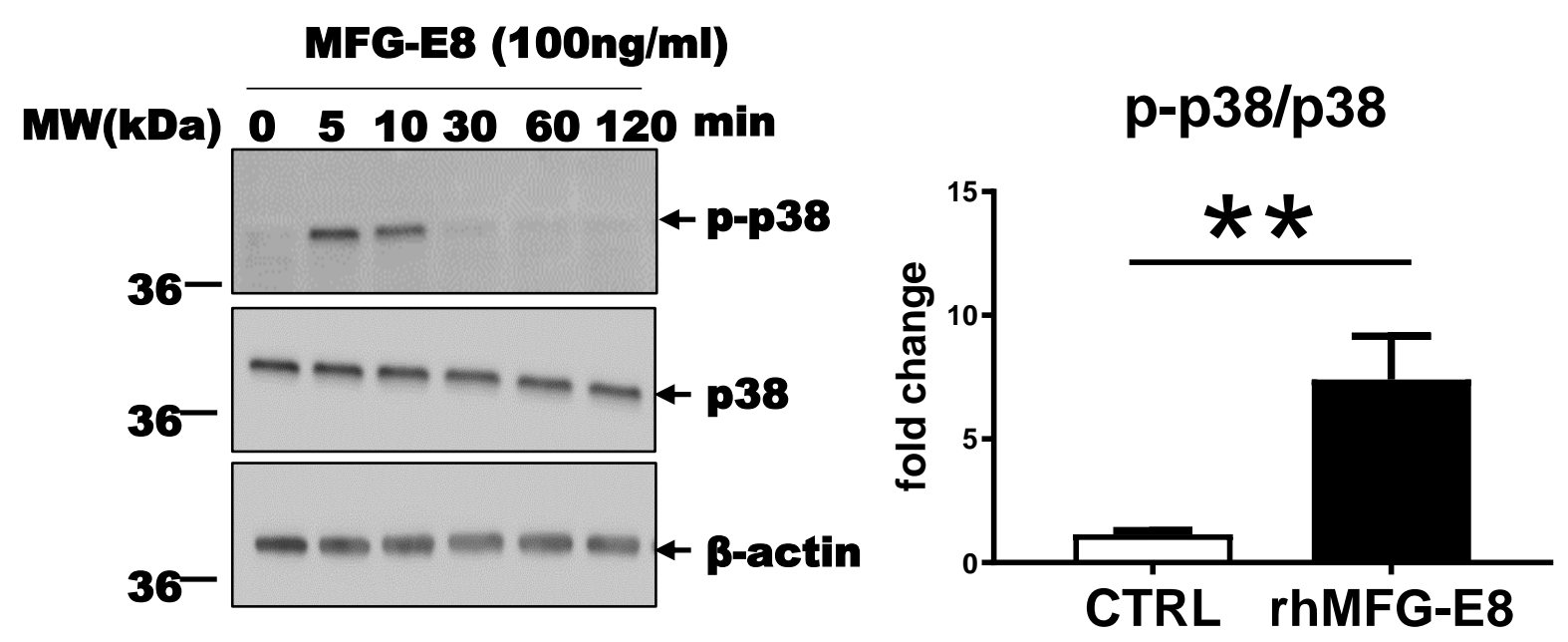
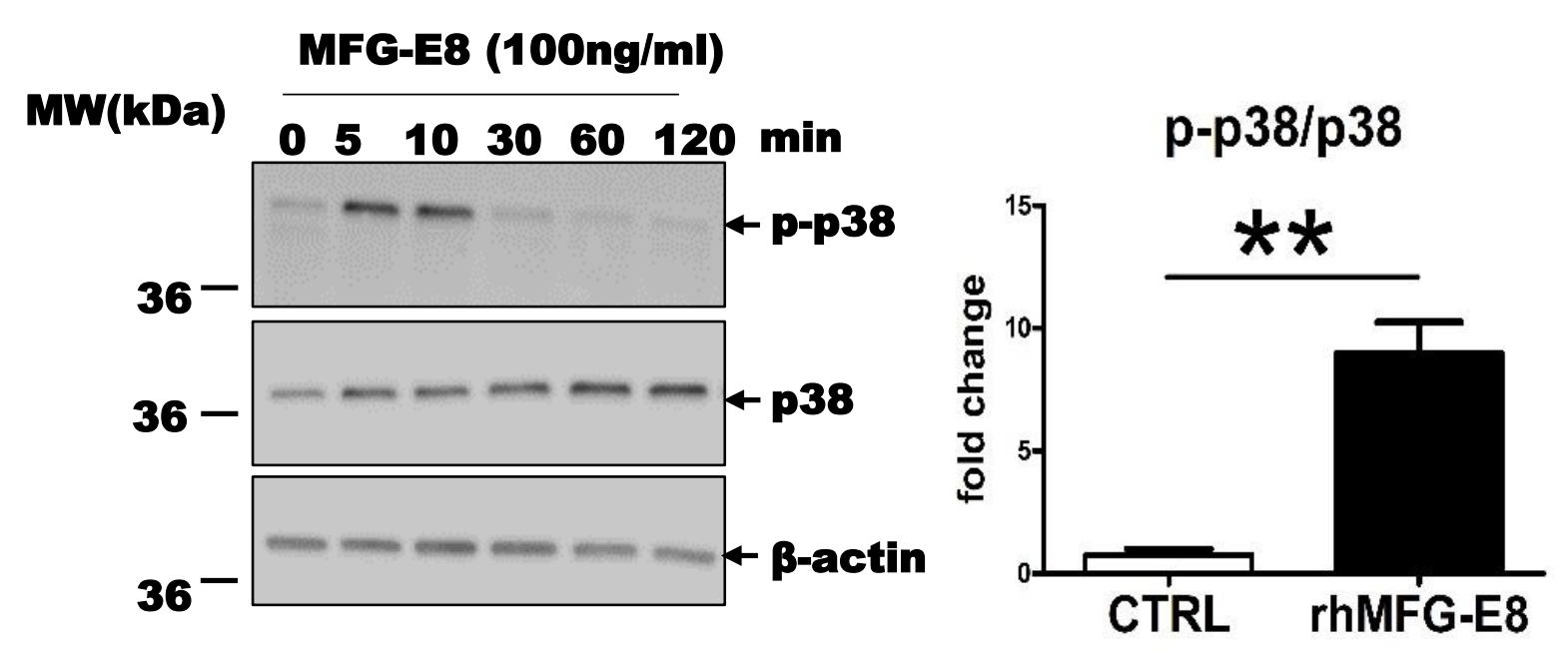

c Young VSMCs

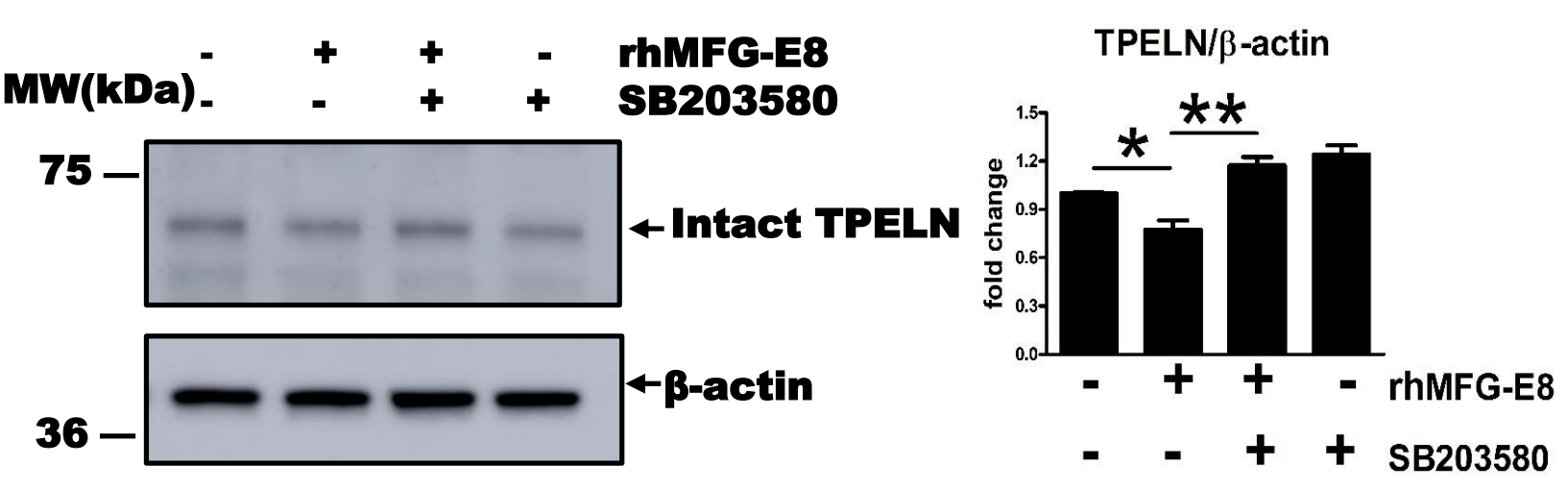

D

\section{Old VSMCs}

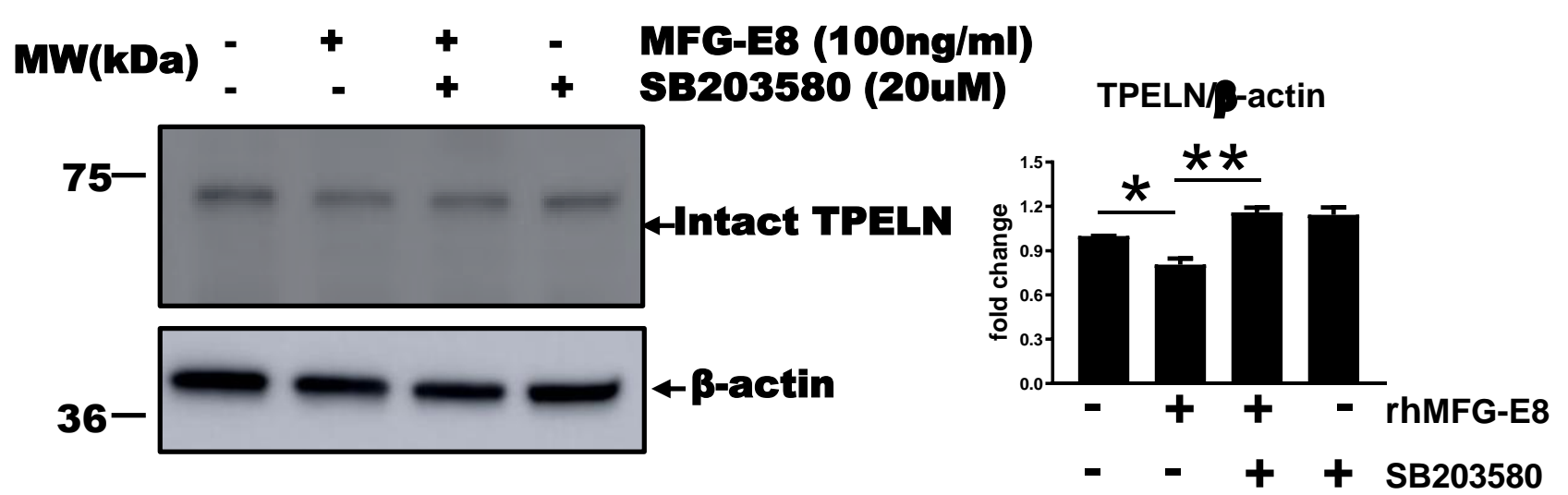


A

Young VSMCs

C
Young VSMCs

Activated MMP-2


Old VSMCs

$$
\text { B }
$$

Activated MMP-2
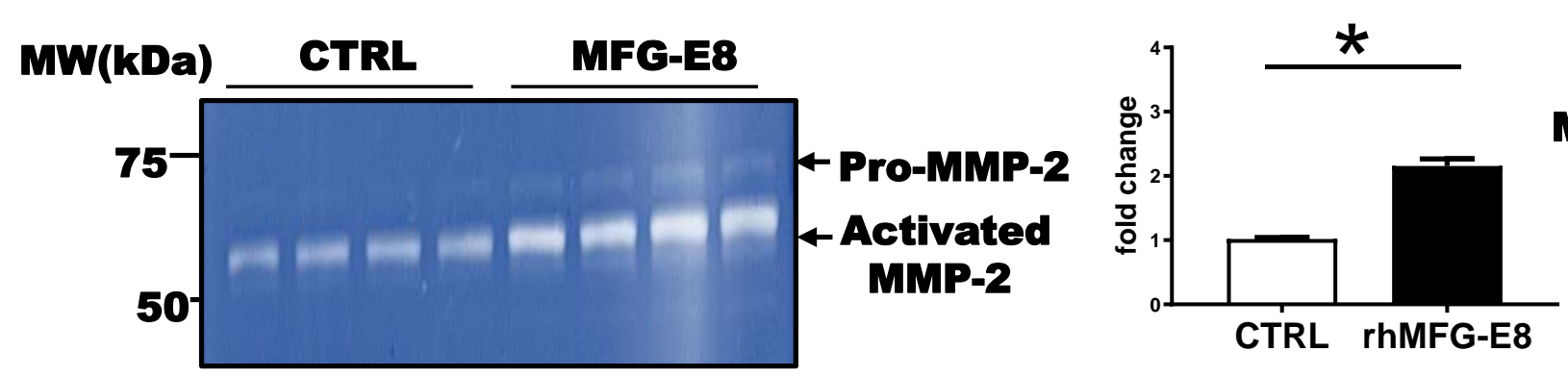

Figure 6
D

Activated MMP-2

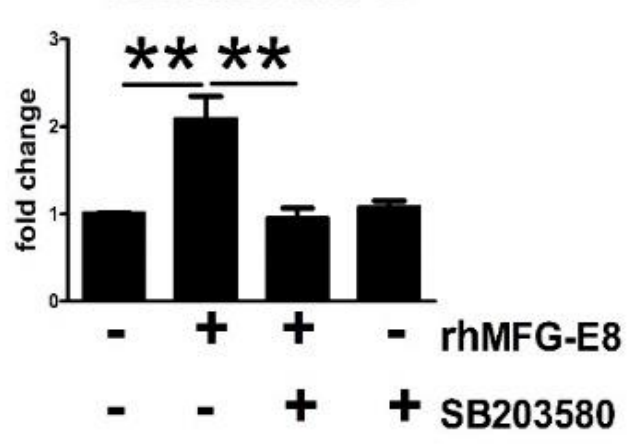

Old Vsmes

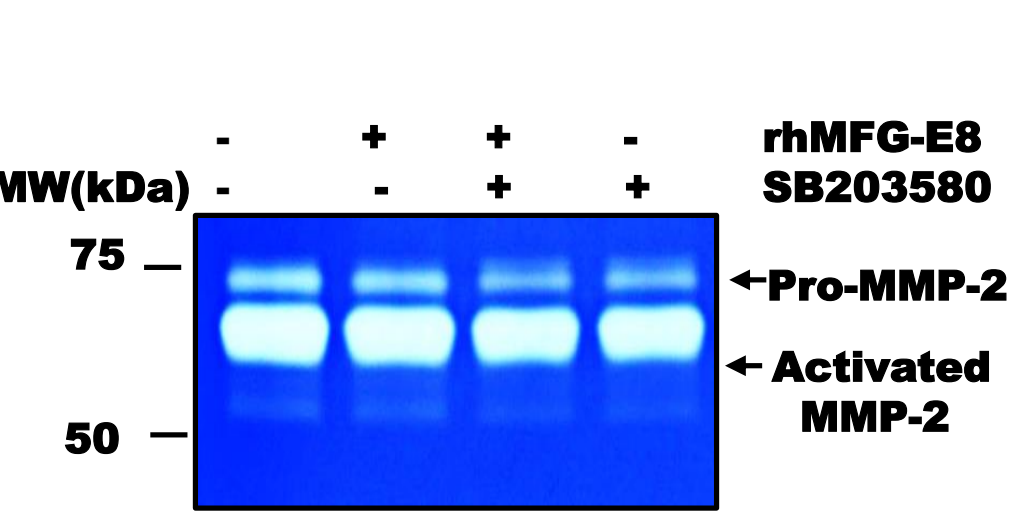

Activated MMP-2




A

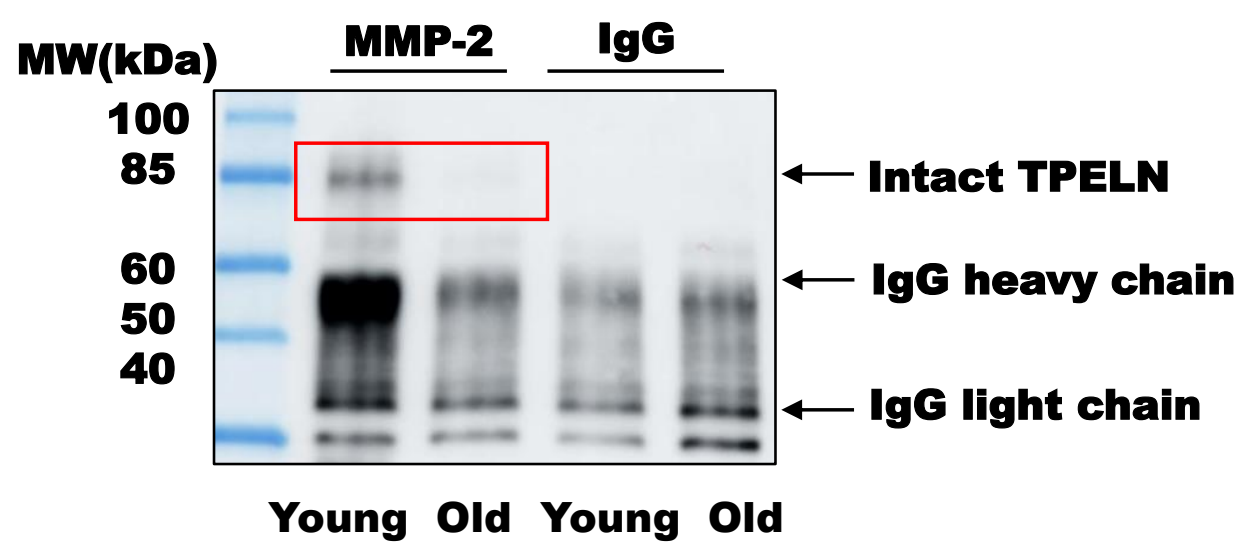

c

Young VSMCs

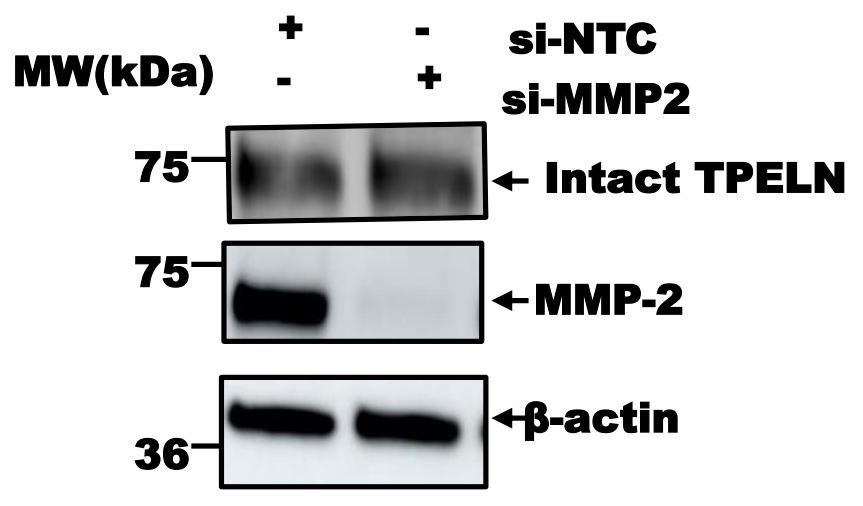

Young VSMCs



D

Old VSMCs

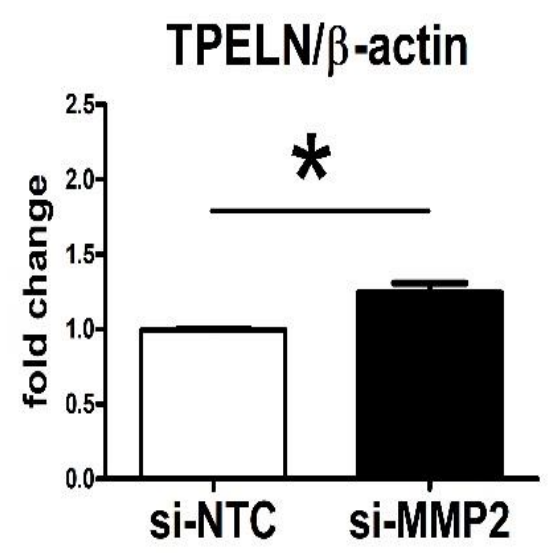

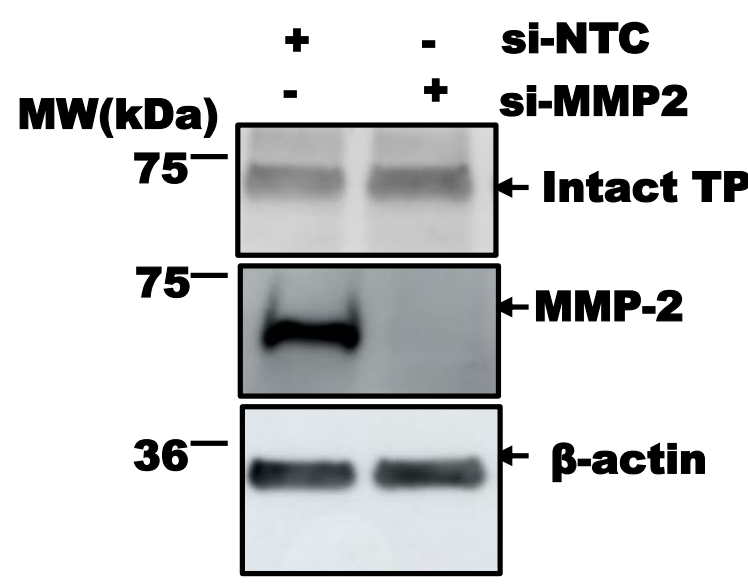

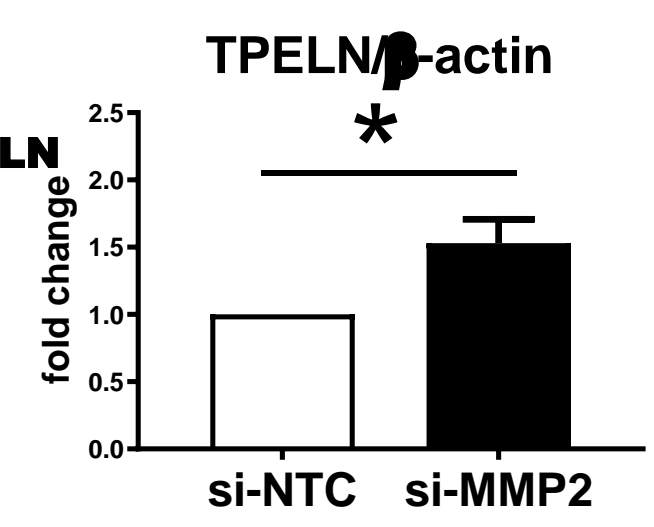


SM22 $\alpha / \beta$-actin
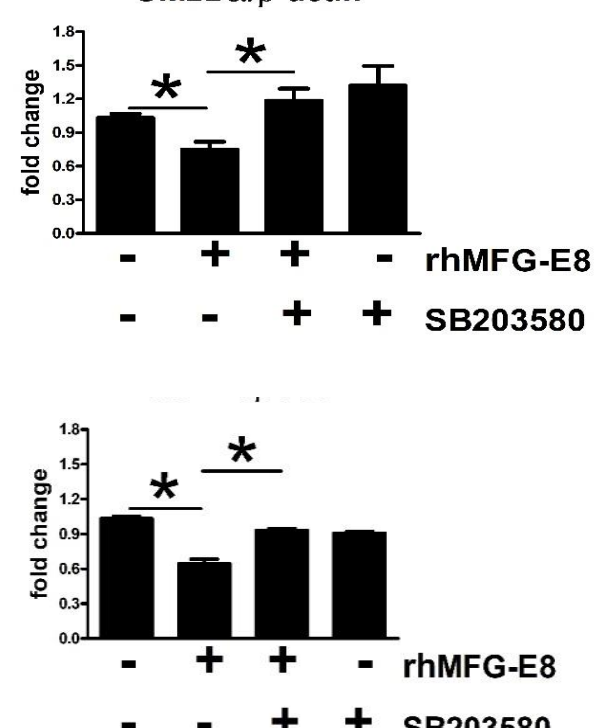

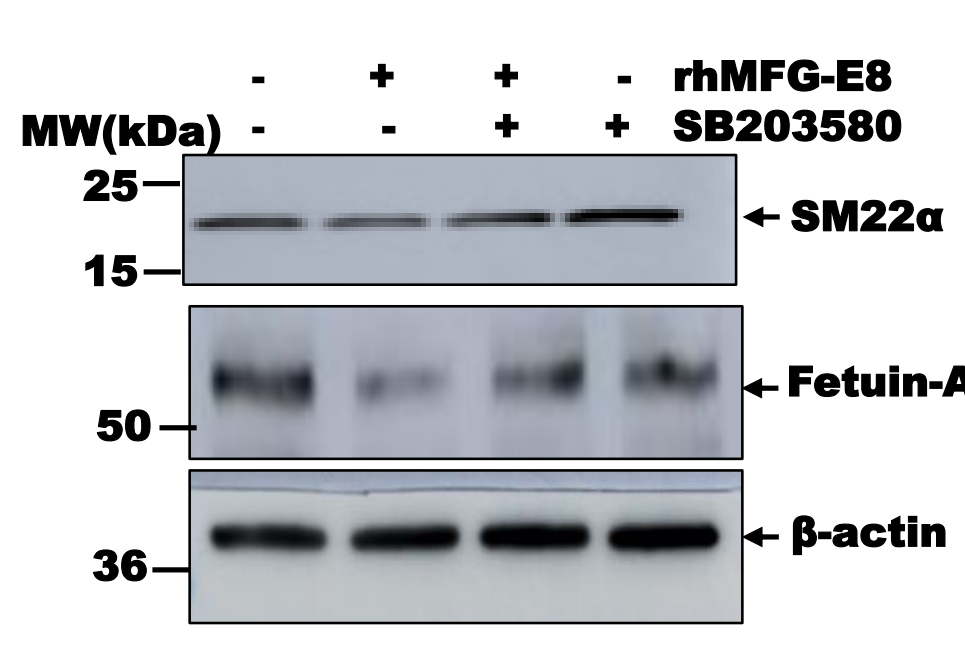

$-\quad+\quad+$ SB203580
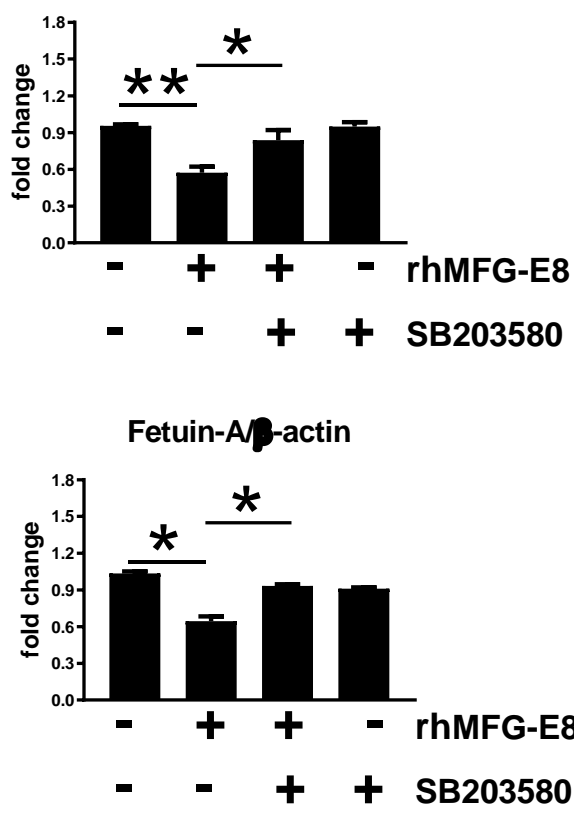

C

\section{Old VSMCs}

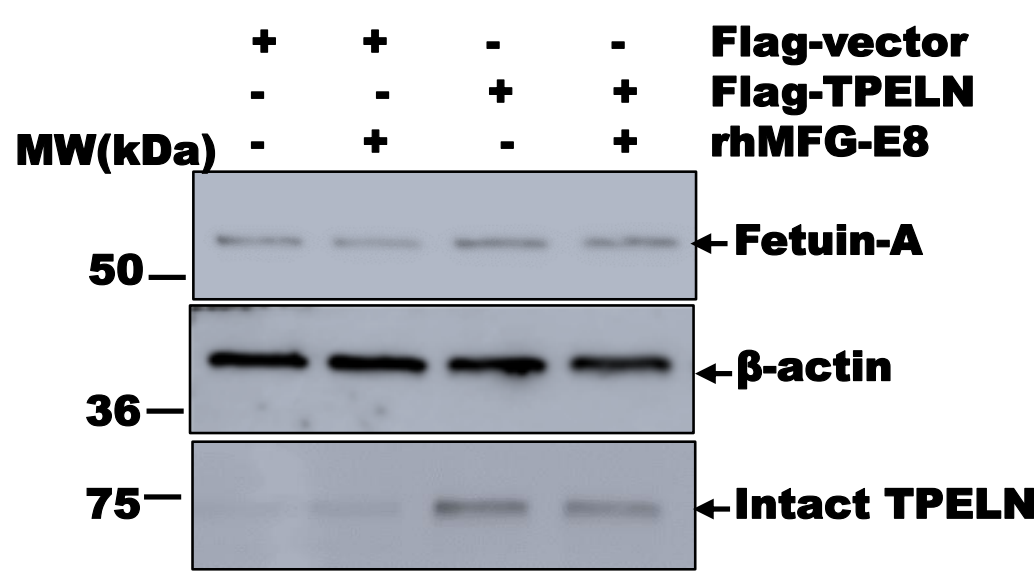

Fetuin-A $\beta$-actin

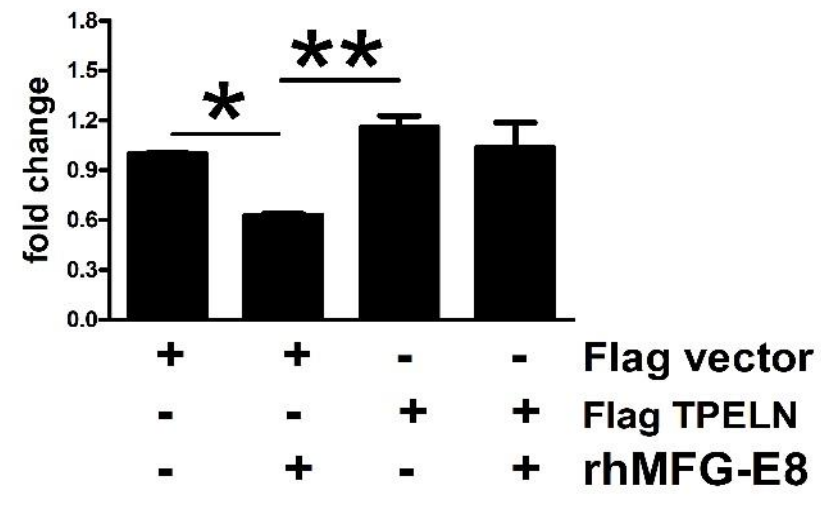


A



B

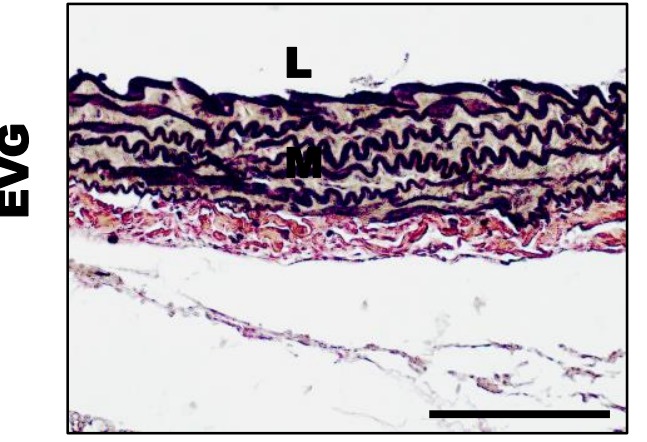

C

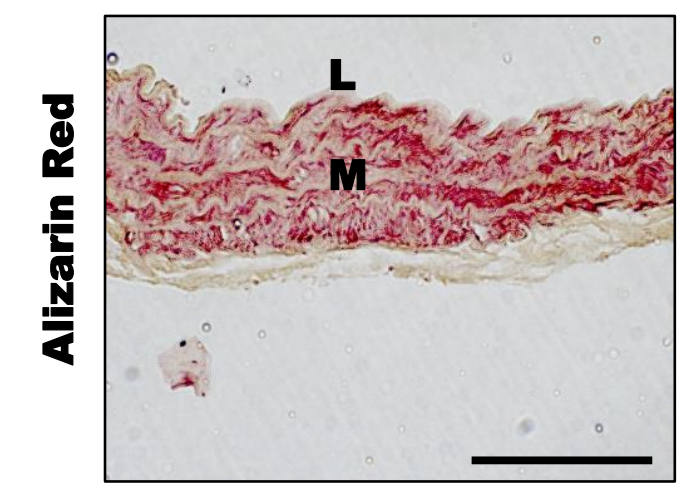

MFG-E8 KO
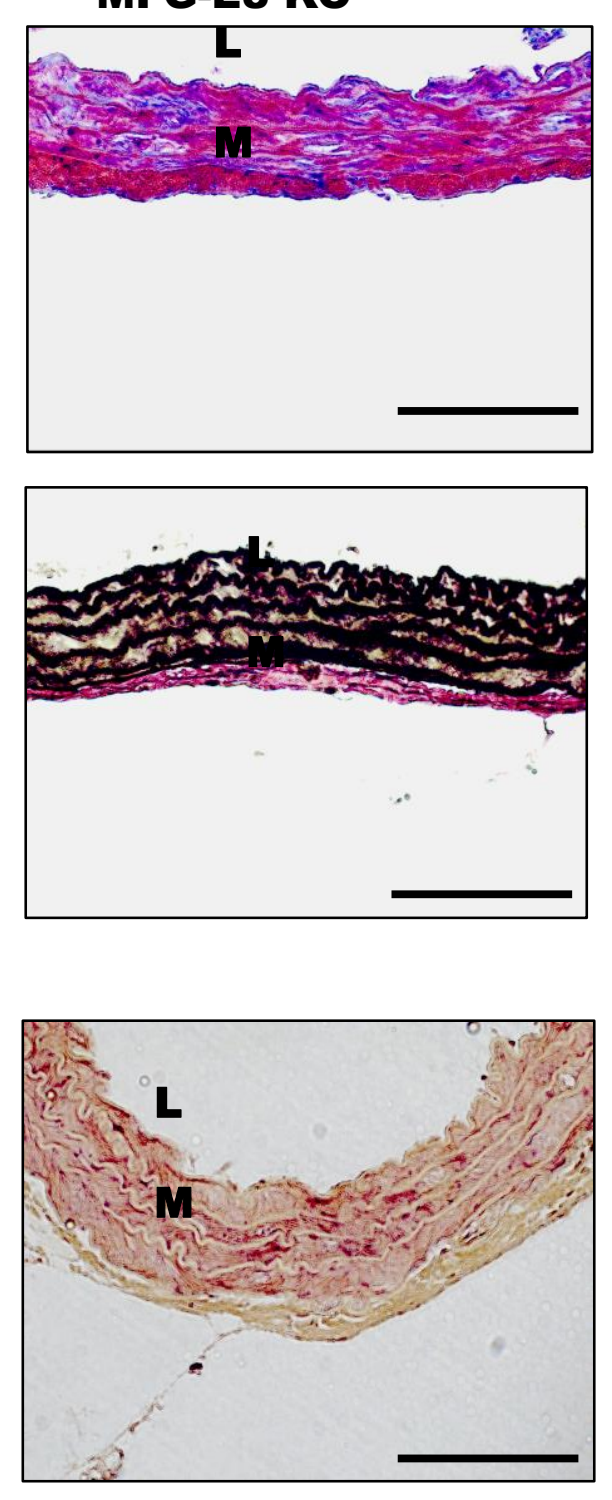
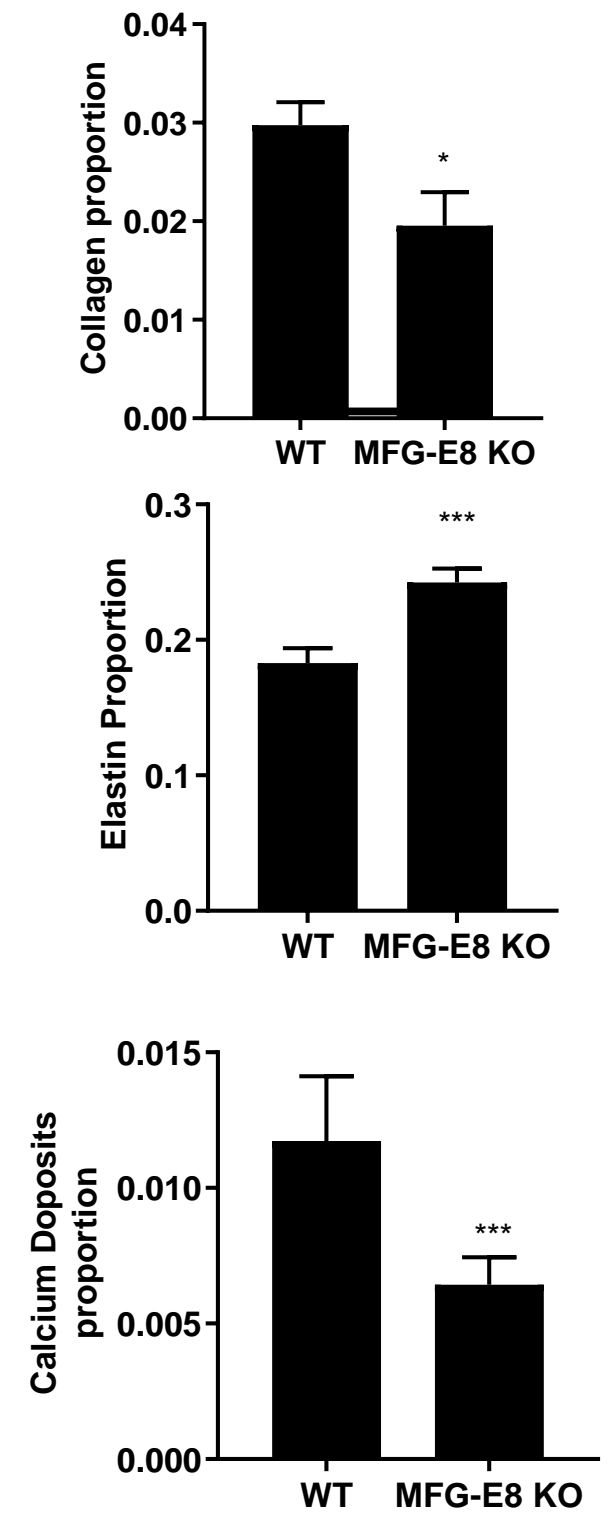

Figure 9 


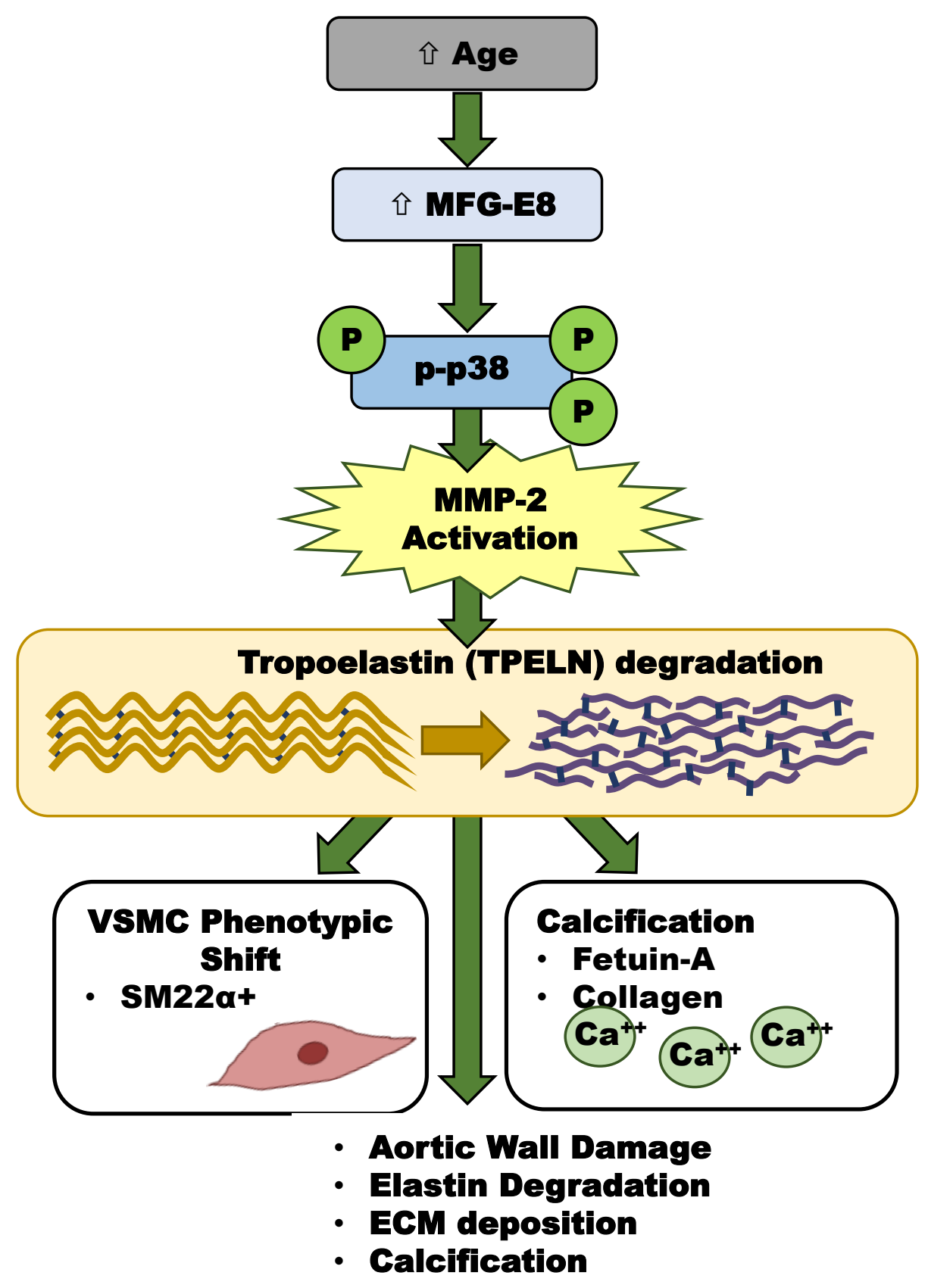

Figure 10 